\title{
Ikoamide, an Antimalarial Lipopeptide from an Okeania sp. Marine Cyanobacterium.
}

\author{
Keitaro Iwasaki ${ }^{\dagger}$, Arihiro Iwasaki ${ }^{\dagger}$, Shimpei Sumimoto ${ }^{\dagger}$, \\ Teruhiko Matsubara ${ }^{\ddagger}$, Toshinori Sato \\ Tomoyoshi Nozaki $^{\S}$, Yumiko Saito-Nakano ${ }^{\perp}$, and Kiyotake Suenaga ${ }^{\dagger}$
}

Department of Chemistry, Faculty of Science and Technology, Keio University, 3-14-1 Hiyoshi, Kohoku-ku, Yokohama, Kanagawa 223-8522, Japan

Department of Biosciences and Informatics, Faculty of Science and Technology, Keio University,

3-14-1 Hiyoshi, Kohoku-ku, Yokohama, Kanagawa 223-8522, Japan

Department of Biomedical Chemistry, Graduate School of Medicine, The University of Tokyo,

7-3-1 Hongo, Bunkyo-ku, Tokyo 113-0033, Japan

${ }^{\perp}$ Department of Parasitology, National Institute of Infectious Diseases, 1-23-1 Toyama, Shinjuku-ku, Tokyo 162-8640, Japan

\section{Contents}

$\mathrm{MS}^{2}$ and $\mathrm{MS}^{3}$ spectra of ikoamide (1) $\mathrm{S} 2$

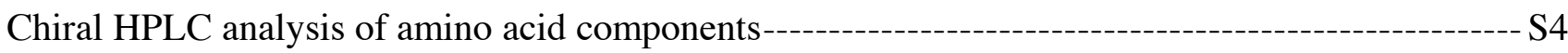

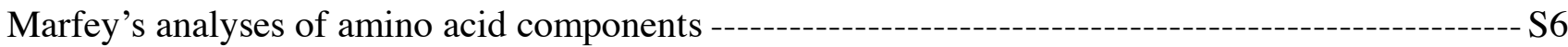

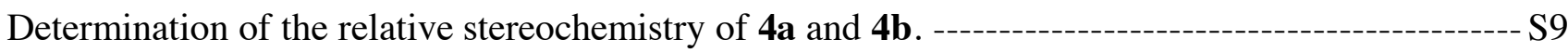

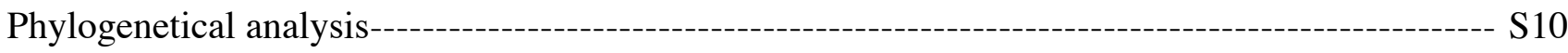

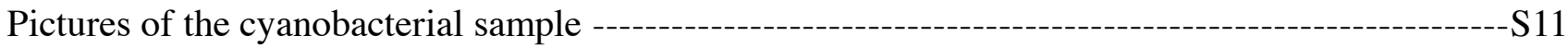

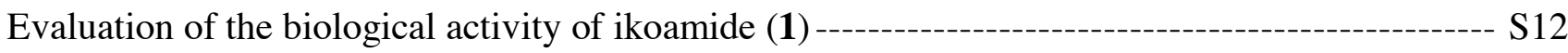

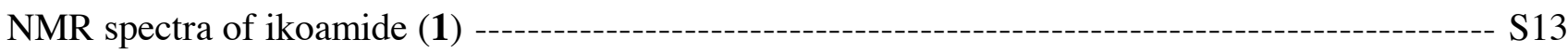

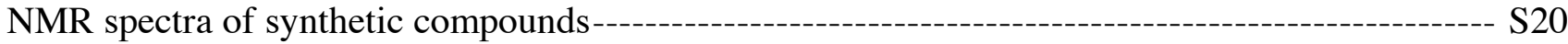

Comparison of 'H NMR spectra of $\mathbf{3}$ from natural ikoamide (1) and synthetic 6a-6d --------------- S42

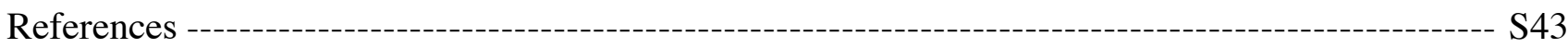




\section{$M^{2}$ and MS ${ }^{\mathfrak{s}}$ spectra of ikoamide (1)}

MS and MS spectra were collected in positive mode. The ESI parameters were as follows: nebulizer, 7.25 psi; dry gas $\left(\mathrm{N}_{2}\right), 4.0 \mathrm{l} / \mathrm{min}$; dry temperature, $179.9{ }^{\circ} \mathrm{C}$; capillary, $4.5 \mathrm{kV}$ for positive ion mode. The mass recorded in survey acquisitions ranged from 50 to $2200 \mathrm{~m} / \mathrm{z}$.

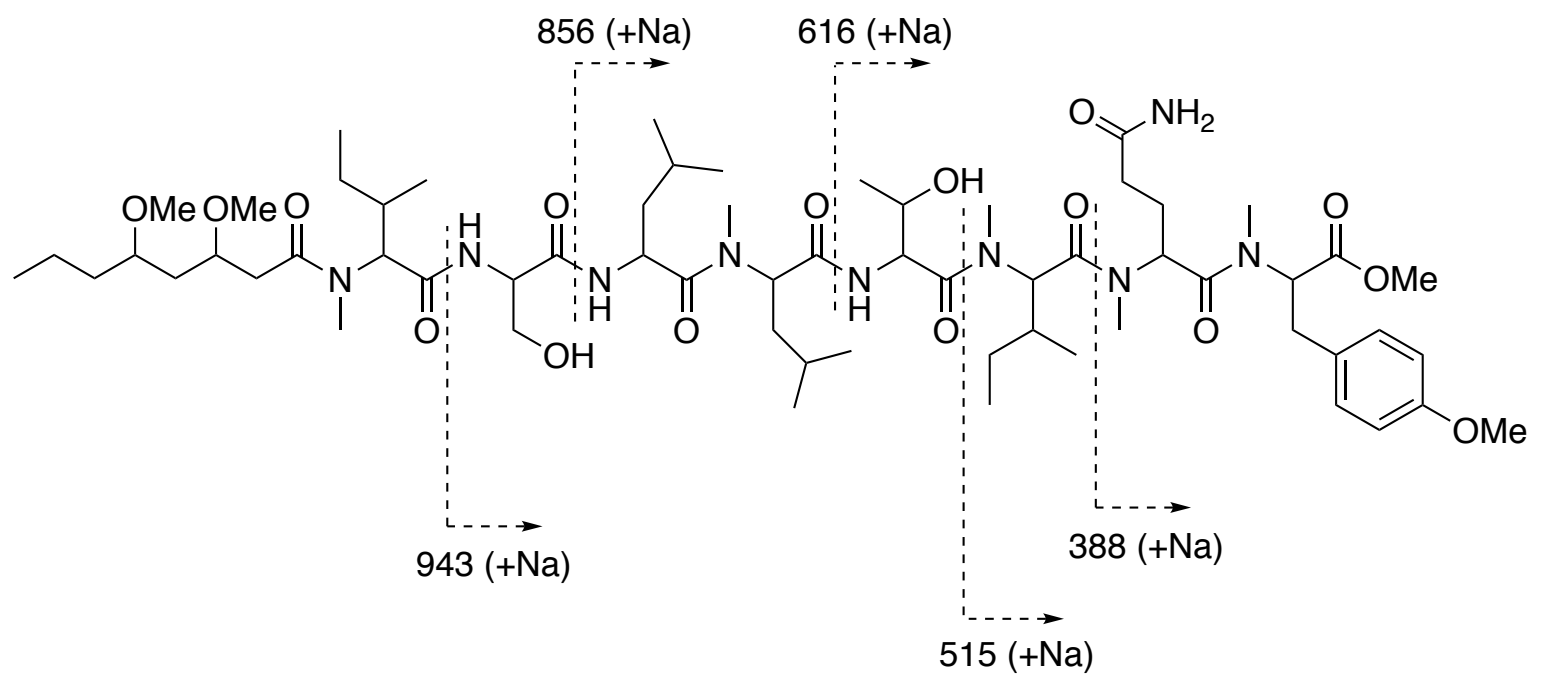

Figure S1. MS ${ }^{2}$ and $\mathrm{MS}^{\mathfrak{s}}$ analyses of ikoamide (1)

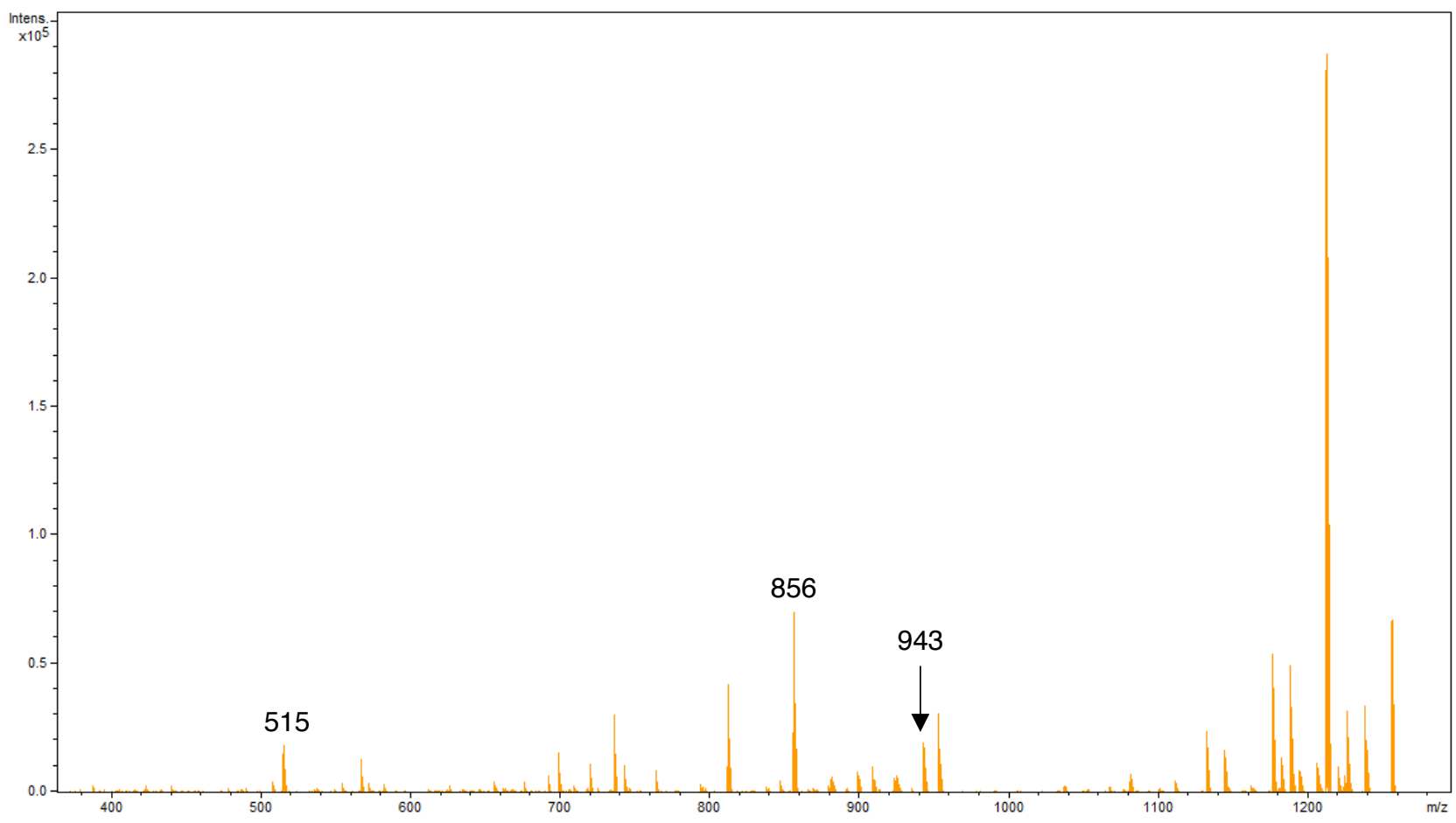

Figure S2. MS's spectrum of ikoamdie (1) (precursor, $m / z, 1256[\mathrm{M}+\mathrm{Na}]^{+}$) 


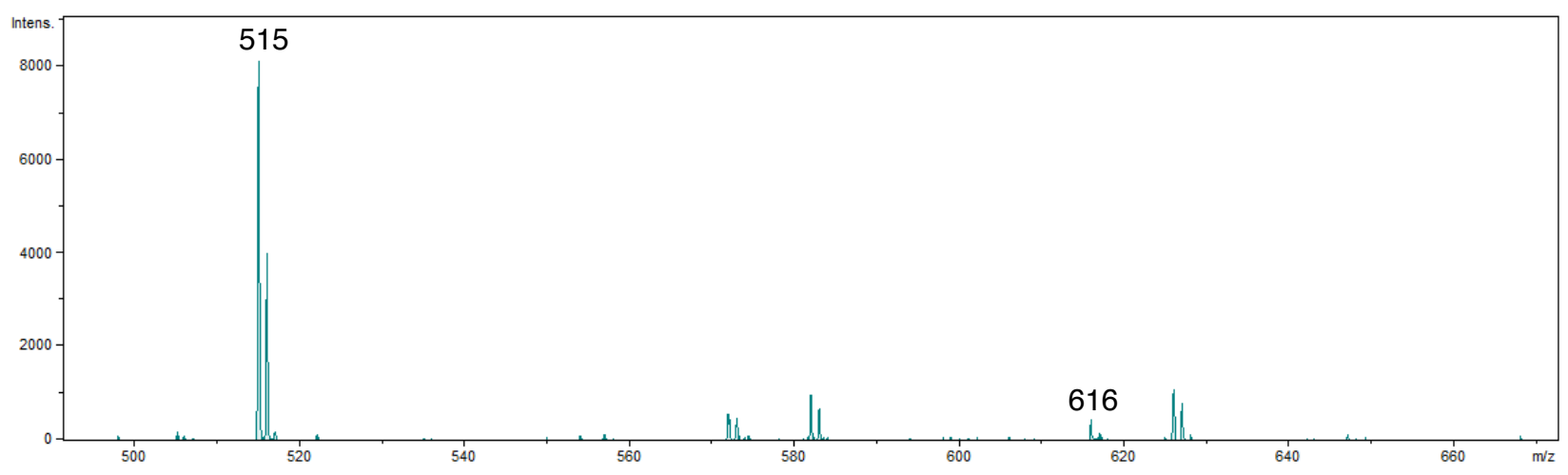

Figure S3. MS ${ }^{3}$ spectrum of a fragment $\left(\mathrm{m} / z 856[\mathrm{M}+\mathrm{Na}]^{+}\right)$from ikoamide (1).

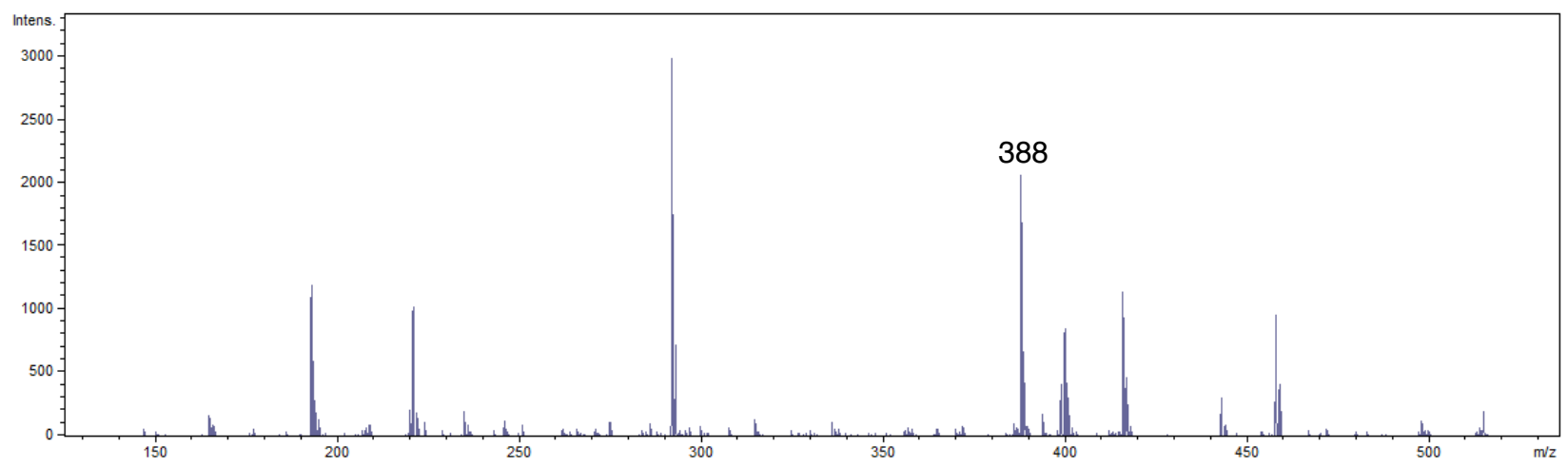

Figure S4. MS ${ }^{3}$ spectrum of a fragment $\left(m / z 515[\mathrm{M}+\mathrm{Na}]^{+}\right)$from ikoamide (1). 


\section{Chiral HPLC analysis of amino acid components}

Leu: column, DAICEL CHIRALPAK $(\mathrm{MA}+)(\phi 4.6 \times 50 \mathrm{~mm})$; flow rate, $1.0 \mathrm{~mL} / \mathrm{min}$; detection at $254 \mathrm{~nm} ; 2.0 \mathrm{mM} \mathrm{CuSO} / \mathrm{MeCN}=95 / 5$

$t_{\mathrm{R}}$ (min): Authentic samples: D-Leu (3.8), L-Leu (5.8)

Leu from hydrolyzed 1 (3.7)

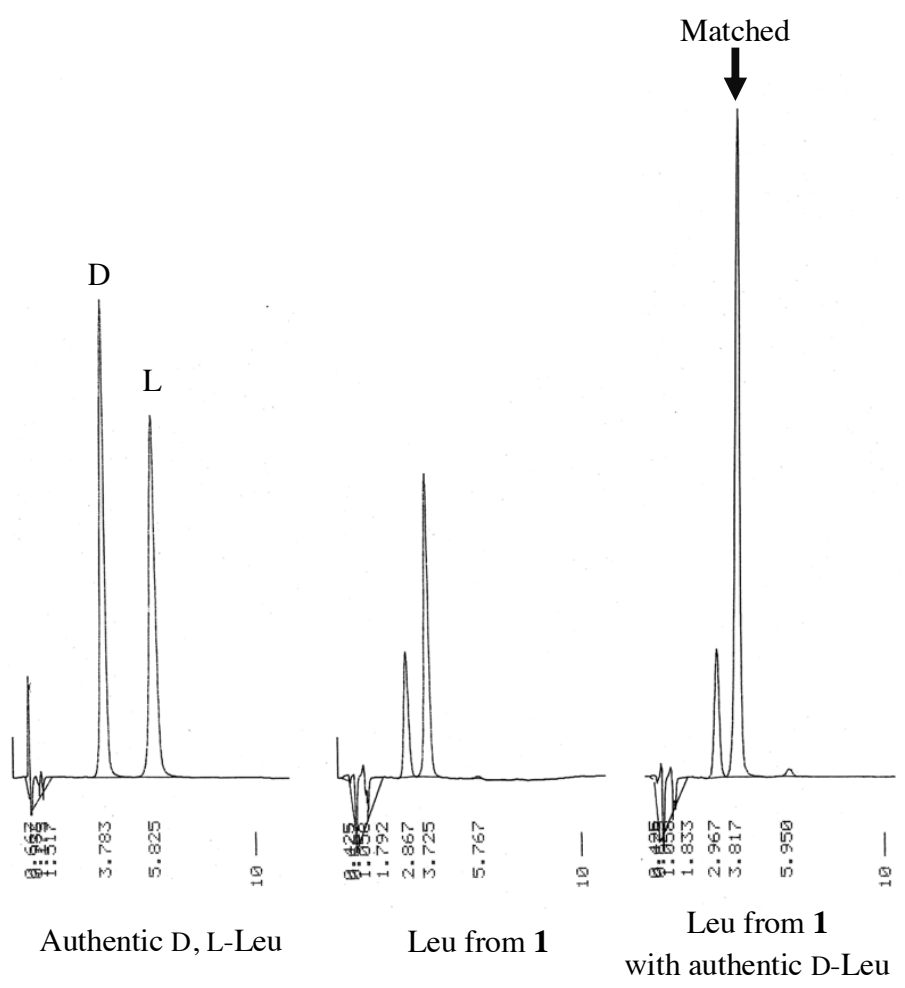


$N$-Me-Leu: column, DAICEL CHIRALPAK (MA+) $(\phi 4.6 \times 50 \mathrm{~mm})$; flow rate, $1.0 \mathrm{~mL} / \mathrm{min}$; detection at $254 \mathrm{~nm} ; 2.0 \mathrm{mM} \mathrm{CuSO} / \mathrm{MeCN}=95 / 5$

$t_{\mathrm{R}}$ (min): Authentic samples: $N$-Me-D-Leu (4.9), $N$-Me-L-Leu (6.9)

$\mathrm{N}$-Me-Leu from hydrolyzed 1 (7.1)

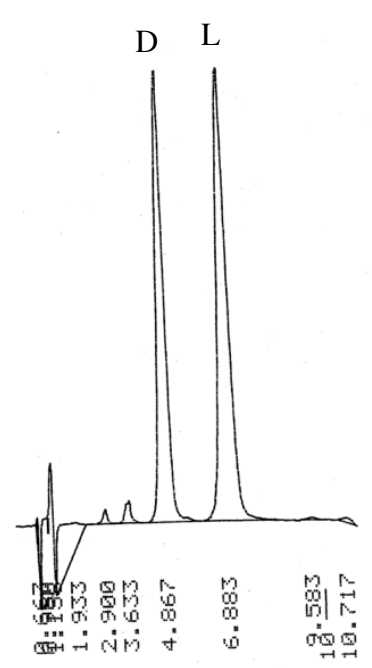

Authentic $N$-Me-D, L-Leu

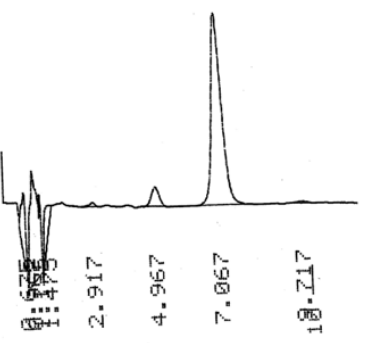

$\mathrm{N}$-Me-Leu from 1

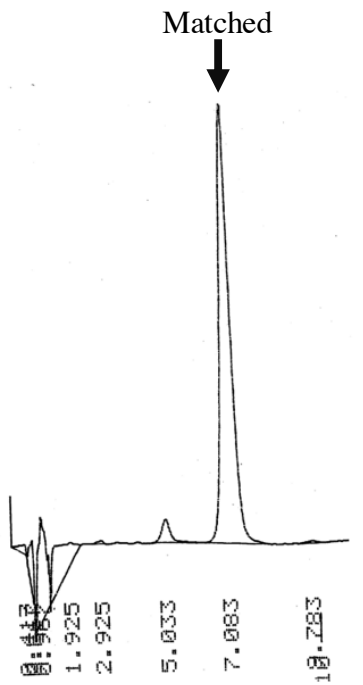

$N$-Me-Leu from 1 with authentic $N$-Me-L-Leu

$N$, $O$-diMe-Tyr: column, DAICEL CHIRALPAK $(\mathrm{MA}+)(\phi 4.6 \times 50 \mathrm{~mm})$; flow rate, $1.0 \mathrm{~mL} / \mathrm{min}$; detection at $254 \mathrm{~nm} ; 2.0 \mathrm{mM} \mathrm{CuSO} / \mathrm{MeCN}=90 / 10$

$t_{\mathrm{R}}$ (min): Authentic samples: $N, O$-diMe-D-Tyr (10.6), $N, O$-diMe-L-Tyr (11.8)

$\mathrm{N}, \mathrm{O}$-diMe-D-Tyr from hydrolyzed 1 (12.0)

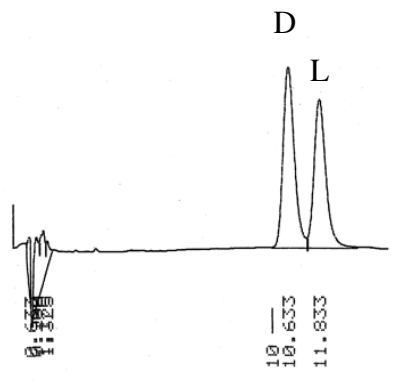

Authentic $N, O$-diMe-D, L-Tyr

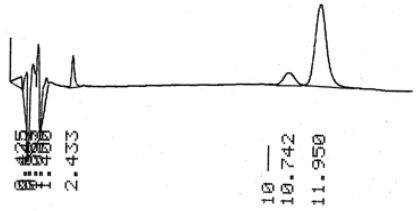

$\mathrm{N}, \mathrm{O}$-diMe-Tyr from 1

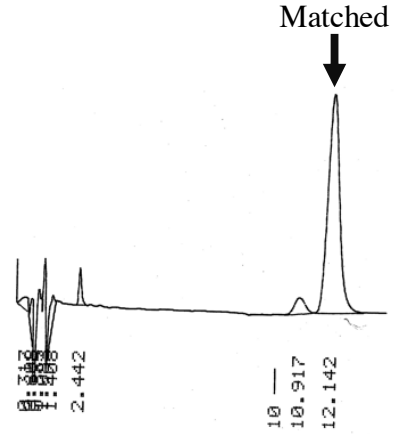

$N, O$-diMe-Tyr from 1 with authentic $N, O$-diMe-L-Tyr 


\section{Marfey's analyses of amino acid components}

$N$-Me-Glu: column, Cosmosil AR-II $(\phi 4.6 \times 250 \mathrm{~mm})$; flow rate, $1.0 \mathrm{~mL} / \mathrm{min}$; detection at $340 \mathrm{~nm} ; 20 \mathrm{mM} \mathrm{NaOAc} / \mathrm{MeOH}=60 / 40$

$t_{\mathrm{R}}(\min )$ : Authentic samples: $N$-Me-L-Glu-L-DLA (7.5), $N$-Me-L-Glu-D-DLA (11.0) $N$-Me-Glu-L-DLA from hydrolyzed 1 (7.4).

$N$-Me-L-Glu-L-DLA

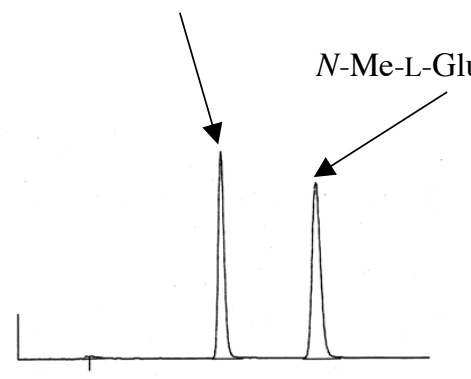

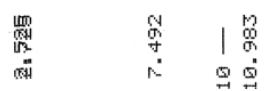

Authentic N-Me-L-Glu-D, L-DLA

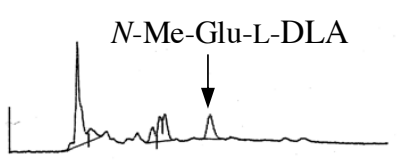

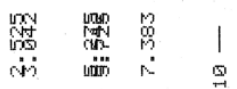

$N$-Me-Glu-L-DLA from 1

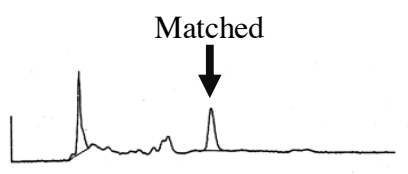

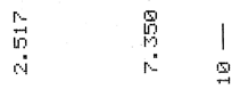

$N$-Me-Glu-L-DLA from 1 with authentic $N$-Me-L-Glu-L-DLA 
Ser: column, Cosmosil $\mathrm{PBr}(\phi 4.6 \times 250 \mathrm{~mm})$; flow rate, $1.0 \mathrm{~mL} / \mathrm{min}$; detection at $340 \mathrm{~nm} ; \mathrm{H}_{2} \mathrm{O} / \mathrm{MeCN}=60 / 40$ with $0.1 \% \mathrm{TFA}$

$t_{\mathrm{R}}(\mathrm{min})$ : Authentic samples: L-Ser-L-DLA (16.1), D-Ser-L-DLA (17.6)

Ser-L-DLA from hydrolyzed 1 (17.6)

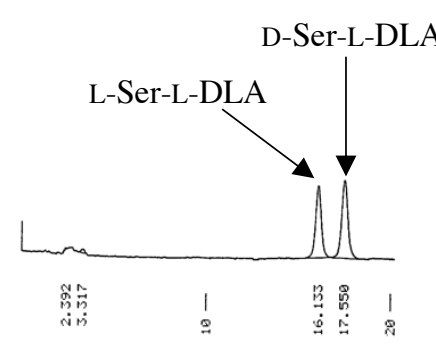

Authentic D, L-Ser-L-DLA

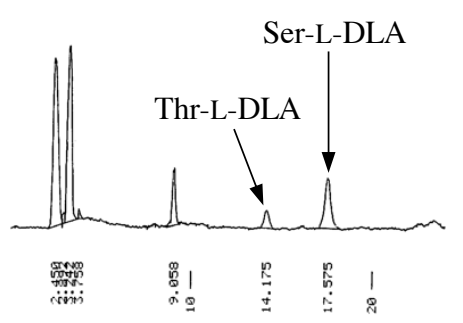

Ser-L-DLA from 1

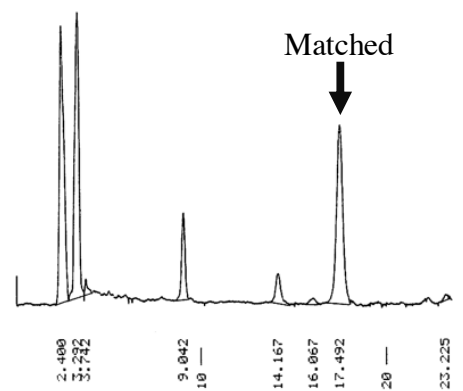

Ser-L-DLA from 1

with authentic D-Ser-L-DLA

Thr: column, Cosmosil $\mathrm{PBr}(\phi 4.6 \times 250 \mathrm{~mm})$; flow rate, $1.0 \mathrm{~mL} / \mathrm{min}$; detection at $340 \mathrm{~nm} ; \mathrm{H}_{2} \mathrm{O} / \mathrm{MeCN}=60 / 40$ with $0.1 \%$ TFA

$t_{\mathrm{R}}(\min )$ : Authentic samples: L-Thr-L-DLA (14.3) L-allo-Thr-L-DLA (16.8),

D-Thr-L-DLA (19.2), D-allo-Thr-L-DLA (20.9)

Thr-L-DLA from hydrolyzed 1 (14.2).

L-allo-Thr-L-DLA

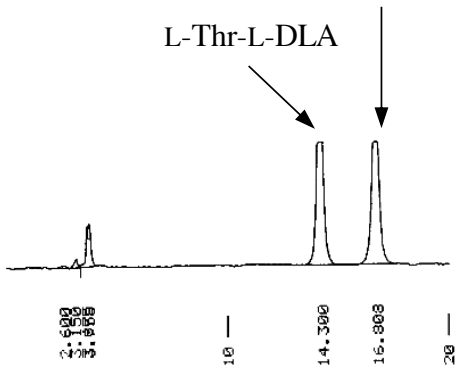

Authentic L-Thr-L-DLA

and L-allo-Thr-L-DLA

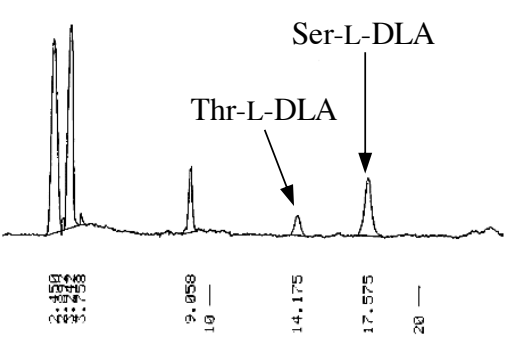

Thr-L-DLA from 1
D-allo-Thr-L-DLA

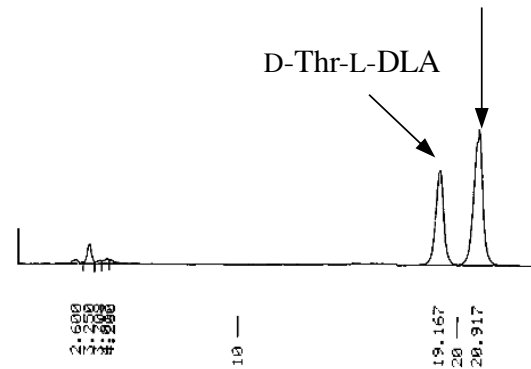

Authentic D-Thr-L-DLA

and D-allo-Thr-L-DLA

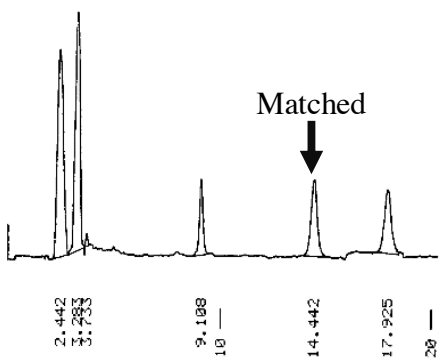

Thr-L-DLA from 1

Authentic L-Thr-L-DLA 
$N$-Me-Ile: column, Cosmosil $\mathrm{PBr}(\phi 4.6 \times 250 \mathrm{~mm})$; flow rate, $1.0 \mathrm{~mL} / \mathrm{min}$; detection at $340 \mathrm{~nm} ; \mathrm{H}_{2} \mathrm{O} / \mathrm{MeCN}=45 / 55$ with $0.1 \%$ TFA

$t_{\mathrm{R}}(\mathrm{min})$ : Authentic samples: $N$-Me-L-Ile-L-DLA (14.0), $N$-Me-D-allo-Ile-D-DLA (14.6),
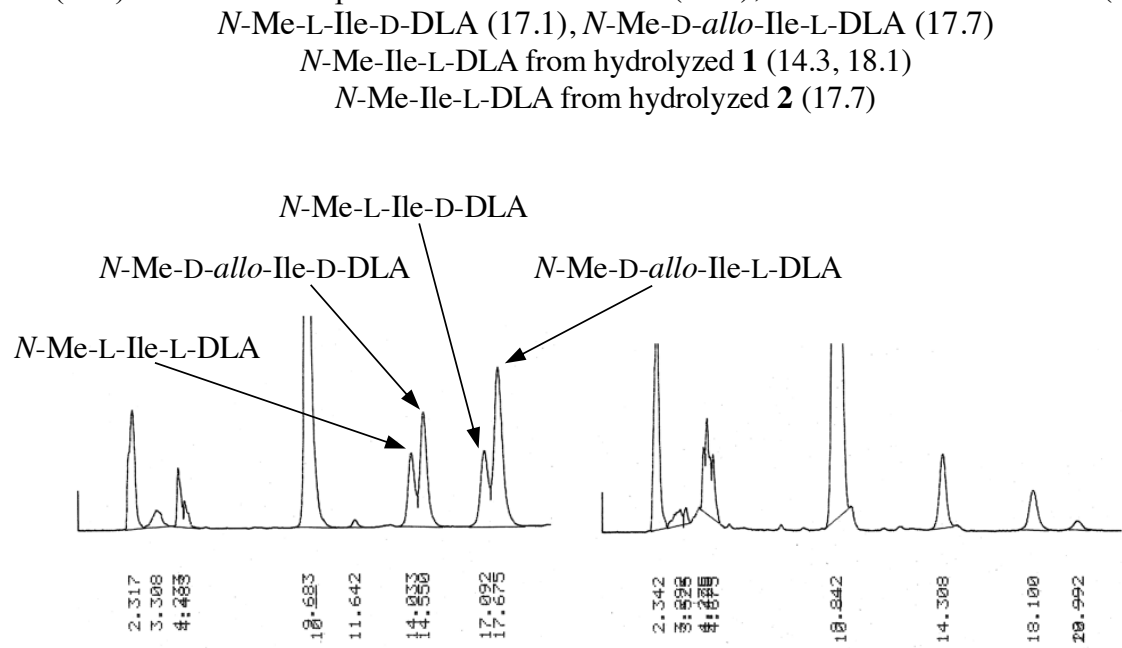

Authentic $N$-Me-L-Ile-D, L-DLA and $N$-Me-D-allo-Ile-D, L-DLA

$\mathrm{N}$-Me-Ile-L-DLA from 1

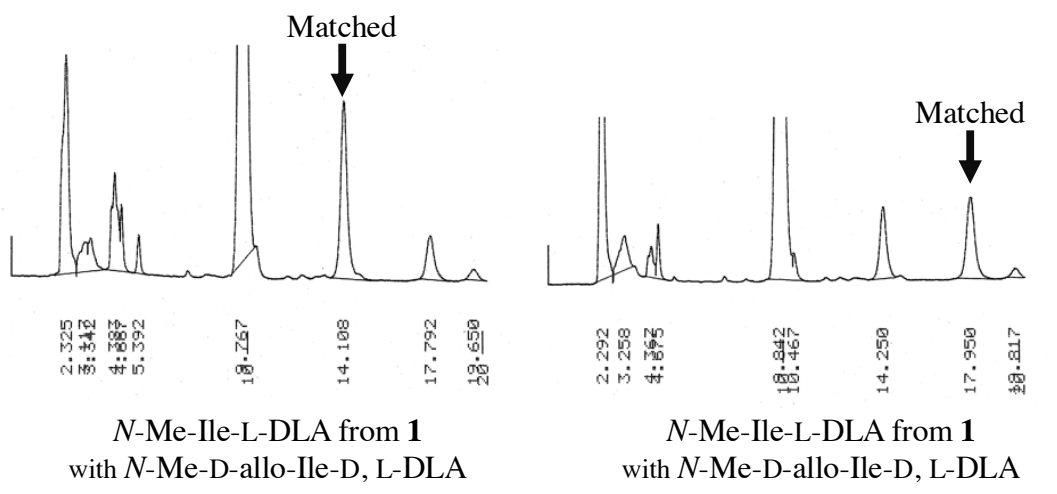

It was clarified that the two $N$-Me-Ile residues in $\mathbf{1}$ were composed of L- and D-allo-forms.
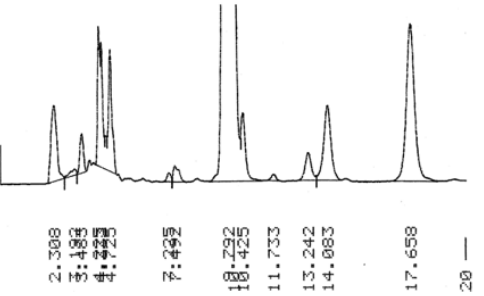

$N$-Me-allo-Ile-L-DLA from 2

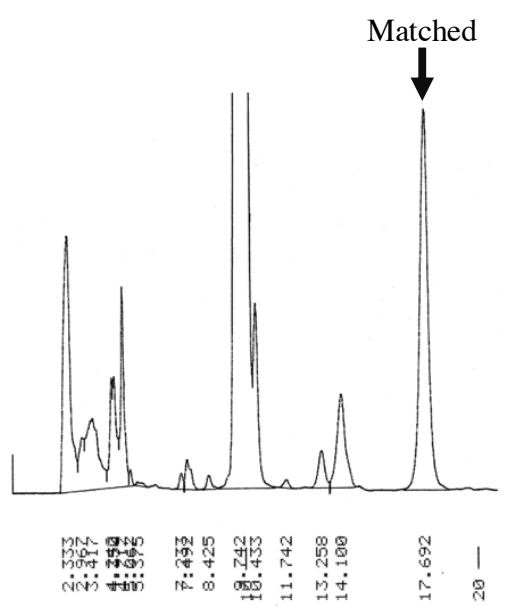

$N$-Me-allo-Ile-L-DLA from 2 with $N$-Me-D-allo-Ile-L-DLA

It was clarified that the $N$-Me-Ile residue in $\mathbf{2}$ was composed of D-allo-form. 


\section{Determination of the relative stereochemistry of $4 \mathrm{a}$ and $\mathbf{4 b}$.}

Scheme S1. Acetonidation of the diol $\mathbf{4 a}$ and $\mathbf{4 b}$

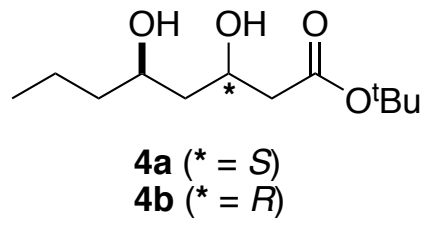

DMP, PTSA, acetone, rt.

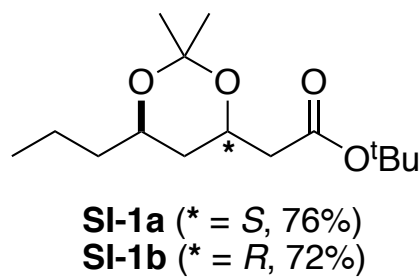

tert-butyl 2-((4S,6R)-2,2-dimethyl-6-propyl-1,3-dioxan-4-yl)acetate (SI-1a):

To a stirred solution of diol $\mathbf{4 a}(10.0 \mathrm{mg}, 43.0 \mu \mathrm{mol})$ in acetone $(500 \mu \mathrm{L})$ was added $p$-toluenesulfonic acid $(4.3 \mathrm{mg}, 25 \mu \mathrm{mol})$ and 2,2-dimethoxypropane $(179 \mathrm{mg}, 1.71 \mathrm{mmol})$. The mixture was then stirred at room temperature for $5 \mathrm{~h}$, and then $0.5 \mathrm{M}$ $\mathrm{NaHCO}_{3}(10 \mathrm{~mL})$ was added. The aqueous layer was extracted with EtOAc $(3 \times 10 \mathrm{~mL})$. The combined organic layers were washed with brine, dried $\left(\mathrm{Na}_{2} \mathrm{SO}_{4}\right)$, filtered and concentrated to give acetonide SI-1a $(8.9 \mathrm{mg}, 32.7 \mu \mathrm{mol}, 76 \%)$. $[\alpha]_{\mathrm{D}^{285}}-23.4(c$ $\left.0.59, \mathrm{CHCl}_{3}\right)$; ${ }^{\mathrm{H}} \mathrm{NMR}\left(400 \mathrm{MHz}, \mathrm{CD}_{3} \mathrm{OD}\right) \delta 4.19(\mathrm{~m}, 1 \mathrm{H}), 3.81(\mathrm{~m}, 1 \mathrm{H}), 2.41(\mathrm{dd}, J=15.4,4.7 \mathrm{~Hz}, 1 \mathrm{H}), 2.31(\mathrm{dd}, J=15.4,9.1$ $\mathrm{Hz}, 1 \mathrm{H}), 1.62(\mathrm{t}, J=7.9 \mathrm{~Hz}, 2 \mathrm{H}), 1.52-1.27(\mathrm{~m}, 4 \mathrm{H}), 1.45(\mathrm{~s}, 9 \mathrm{H}), 1.32(\mathrm{~s}, 3 \mathrm{H}), 1.30(\mathrm{~s}, 3 \mathrm{H}), 0.92(\mathrm{t}, J=7.0 \mathrm{~Hz}, 3 \mathrm{H})$; $\mathrm{C}$ NMR $\left(100 \mathrm{MHz}, \mathrm{CD}_{3} \mathrm{OD}\right) \delta 172.2,101.6,81.8,67.6,65.3,43.1,39.1,39.0,28.3,25.2,24.9,19.6,14.3$; IR (neat) 2960, 2937, 2873, $1733,1368,1155 \mathrm{~cm}+$; HRMS (ESI-TOF) $m / z: 295.1878[\mathrm{M}+\mathrm{Na}]+\left(\right.$ calcd for $\mathrm{C}_{15} \mathrm{H}_{28} \mathrm{O}_{4} \mathrm{Na}, 295.1885$ )

tert-butyl 2-((4R,6R)-2,2-dimethyl-6-propyl-1,3-dioxan-4-yl)acetate (SI-1b)

To a stirred solution of diol $\mathbf{4 b}(10.0 \mathrm{mg}, 43.0 \mu \mathrm{mol})$ in acetone $(500 \mu \mathrm{L})$ was added $p$-toluenesulfonic acid $(4.3 \mathrm{mg}, 25 \mu \mathrm{mol})$ and 2,2-dimethoxypropane $(179 \mathrm{mg}, 1.71 \mathrm{mmol})$. The mixture was then stirred at room temperature for $5 \mathrm{~h}$, and then $0.5 \mathrm{M}$ $\mathrm{NaHCO}_{3}(10 \mathrm{~mL})$ was added. The aqueous layer was extracted with EtOAc $(3 \times 10 \mathrm{~mL})$. The combined organic layers were washed with brine, dried $\left(\mathrm{Na}_{2} \mathrm{SO}_{4}\right)$, filtered and concentrated to give acetonide SI-1b $(8.4 \mathrm{mg}, 31.0 \mu \mathrm{mol}, 72 \%)$. [ $\left.\alpha\right]_{\mathrm{D}^{285}}+6.9(c$ $\left.0.56, \mathrm{CHCl}_{3}\right)$; ${ }_{\mathrm{H}} \mathrm{NMR}\left(400 \mathrm{MHz}, \mathrm{CD}_{3} \mathrm{OD}\right) \delta 4.29(\mathrm{~m}, 1 \mathrm{H}), 3.91(\mathrm{~m}, 1 \mathrm{H}), 2.36(\mathrm{dd}, J=15.4,5.4 \mathrm{~Hz}, 1 \mathrm{H}), 2.29(\mathrm{dd}, J=15.4,8.2$ $\mathrm{Hz}, 1 \mathrm{H}), 1.57(\mathrm{dt}, J=13.1,2.5 \mathrm{~Hz}, 1 \mathrm{H}), 1.52-1.27(\mathrm{~m}, 4 \mathrm{H}), 1.45(\mathrm{~s}, 9 \mathrm{H}), 1.44(\mathrm{~s}, 3 \mathrm{H}), 1.31(\mathrm{~s}, 3 \mathrm{H}), 1.10(\mathrm{dt}, J=13.1,11.7 \mathrm{~Hz}$, $1 \mathrm{H}), 0.92(\mathrm{t}, J=7.4 \mathrm{~Hz}, 3 \mathrm{H})$; ${ }^{\mathrm{C} C \mathrm{NMR}}\left(100 \mathrm{MHz}, \mathrm{CD}_{3} \mathrm{OD}\right) \delta 172.2,99.9,81.8,69.9,67.7,43.7,39.6,37.7,30.4,28.3,20.0,19.2$, 14.3; IR (neat) 2960, 2936, 2874, 1734, 1368, $1155 \mathrm{~cm}^{-}$; HRMS (ESI-TOF) $\mathrm{m} / z: 295.1892[\mathrm{M}+\mathrm{Na}]^{+}\left(\right.$calcd for $\mathrm{C}_{15} \mathrm{H}_{28} \mathrm{O}_{4} \mathrm{Na}$, 295.1885)

We determined the relative stereochemistry of acetonides by the previously reported method. The $\mathrm{C}$ NMR chemical shifts of acetonides revealed that SI-1a was anti-1,3-diol acetonide and SI-1b was syn-1,3-diol acetonide.

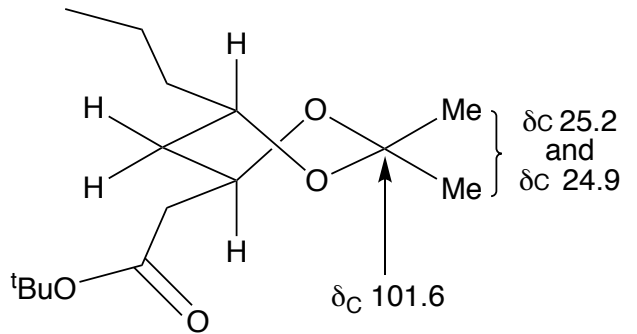<smiles>C#C</smiles><smiles>CCCOC(=O)C[C@@H]1CC(CCC)OC(C)(C)O1</smiles>

SI-1a (anti)

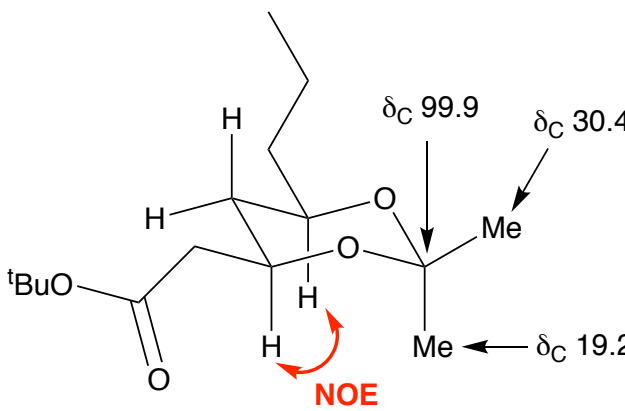<smiles>C#CC</smiles><smiles>CCCCOC(=O)CC1CC(CCC)OC(C)(C)O1</smiles>

Figure S5. Determination of relative stereochemistry of SI-1a and SI-1b 


\section{Phylogenetical analysis}

The nucleotide sequence of 16S rRNA gene obtained in this study was used for phylogenetic analysis with the sequences of related cyanobacterial $16 \mathrm{~S}$ rRNA genes that have been previously reported ${ }^{2}$. All sequences were aligned by SINA web service (version 1.2.11) with default settings. The poorly aligned positions and divergent regions were removed by Gblocks Server ${ }^{*, s}$ (version 0.91b), implementing the options for a less stringent selection, including the 'Allow smaller final blocks', 'Allow gap positions within the final blocks' and 'Allow less strict flanking positions' options. The obtained 570 nucleotide positions were used for phylogenetic analysis. SMS ${ }^{`}$ with default settings was used to select the best model of DNA substitution for the Maximum Likelihood (ML) analysis and Bayesian analysis according to the Akaike information criterion (AIC). The ML analysis was conducted by PhyML (version 3.1), using the GTR+I+G model with a gamma shape parameter of 0.592 and a proportion of invariant sites of 0.516 . Bootstrap resampling was performed on 1000 replicates. The ML tree was visualized with Njplot ${ }^{8}$ (version 2.3). The Bayesian analysis was conducted by MrBayes` (version 3.2.6) using the GTR+I+G model. The Markov chain Monte Carlo process was set at 2 chains, and 1000000 trees were conducted. Sampling frequency was assigned at every 500 generations. After analysis, the first 100000 trees were deleted as burn-in, and the consensus tree was constructed. The Bayesian tree was visualized with FigTree (version 1.4.3). These results showed the collected cyanobacteria 1802-18 was grouped with Okeania sp. Therefore, we decided that the cyanobacterium was classified into the Okeania sp.

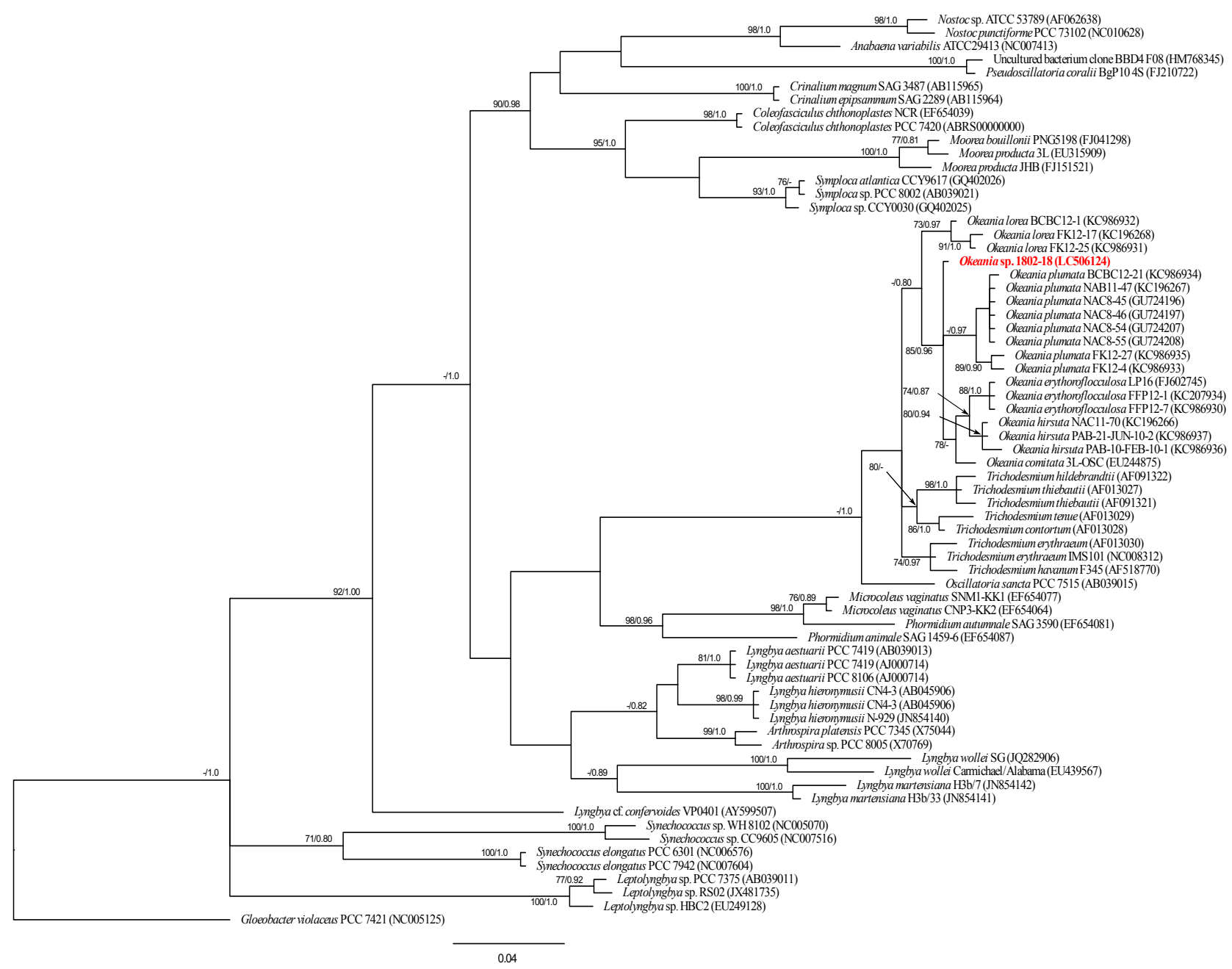

Figure S6. Phylogenetic tree inferred from 16S rDNA sequences using the Bayesian method. The phylogeny is rooted with Gloeobacter violaceus PCC 7421 . The numbers at the nodes indicate bootstrap values (values $<70 \%$ are not shown) and posterior probability (values $<0.8$ are not shown) for the ML/Bayesian inference. 
Pictures of the cyanobacterial sample
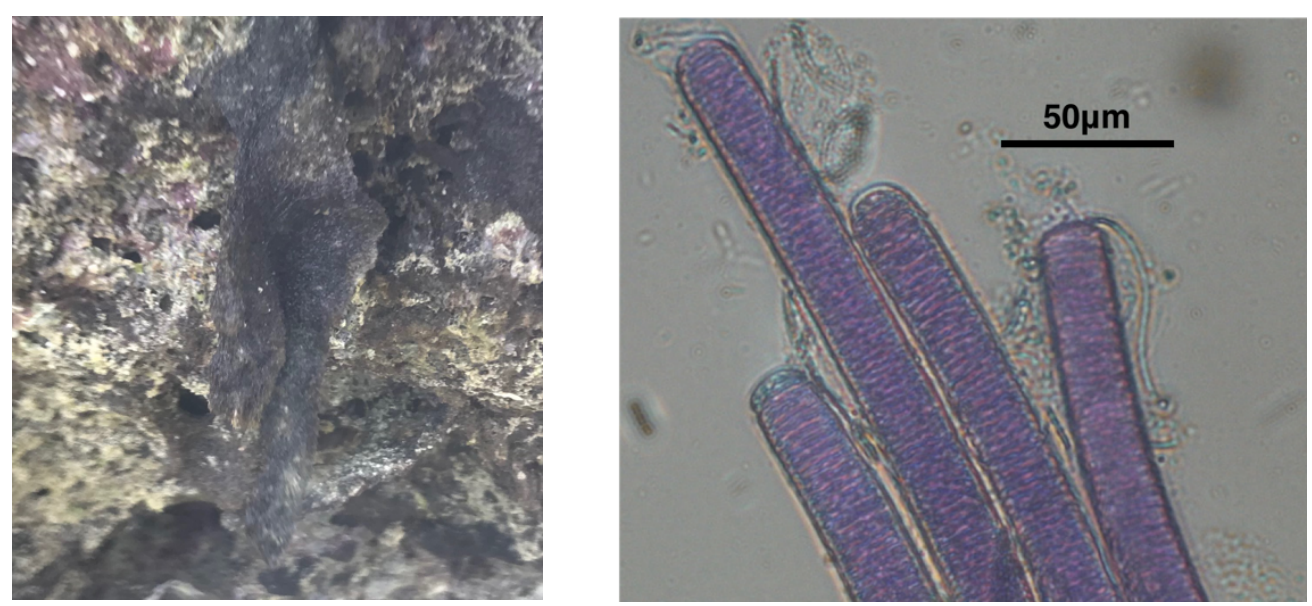

Figure S6. In situ picture and microscopic picture of cyanobacterial sample Okeania sp. 1802-18 

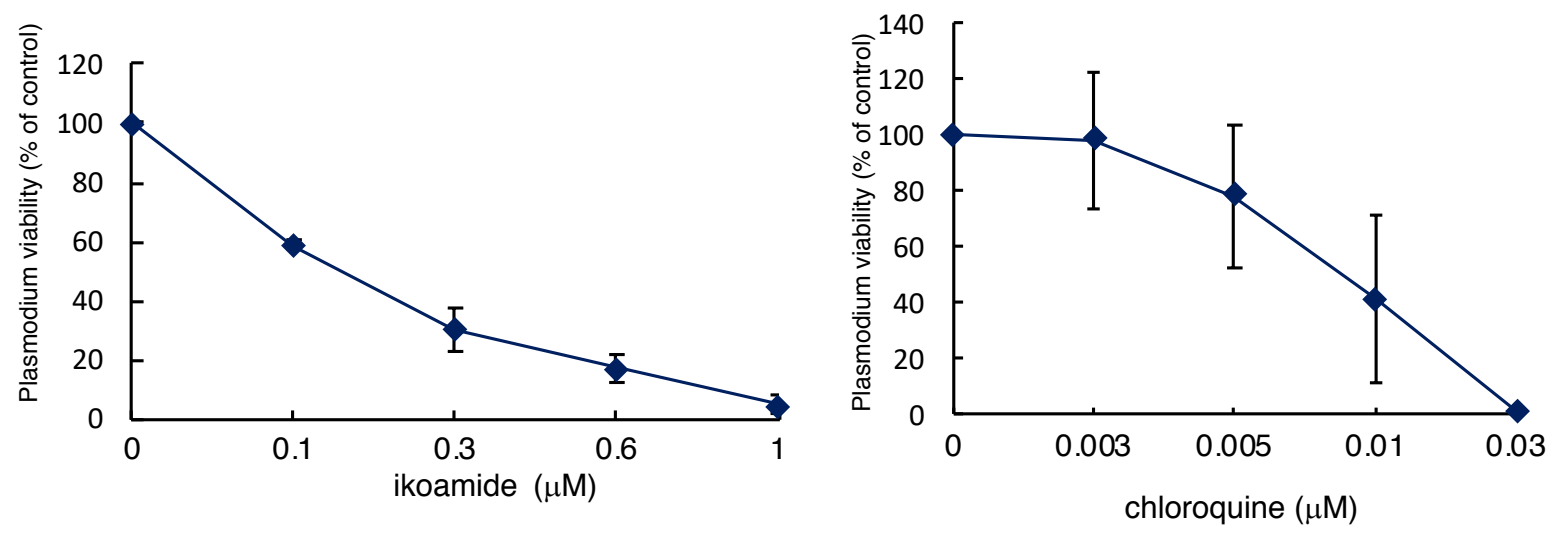

Figure S7. The dose-response curves against Plasmodium falciparum $(\mathrm{n}=3)$.
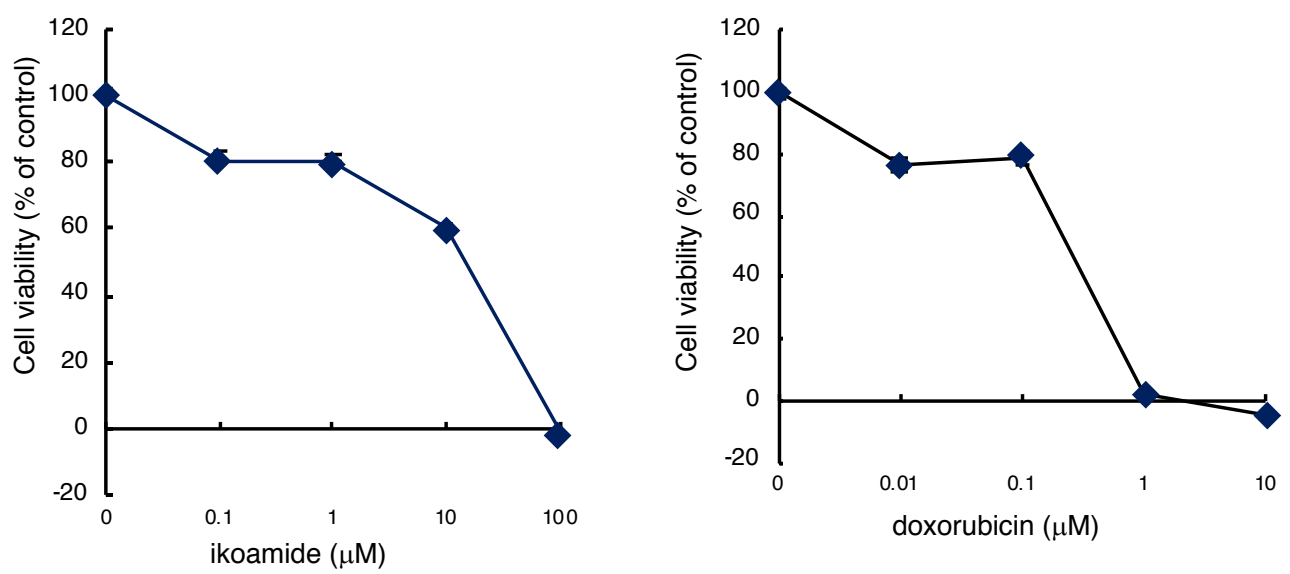

Figure S8. The dose-response curves against HeLa cells $(\mathrm{n}=3)$.
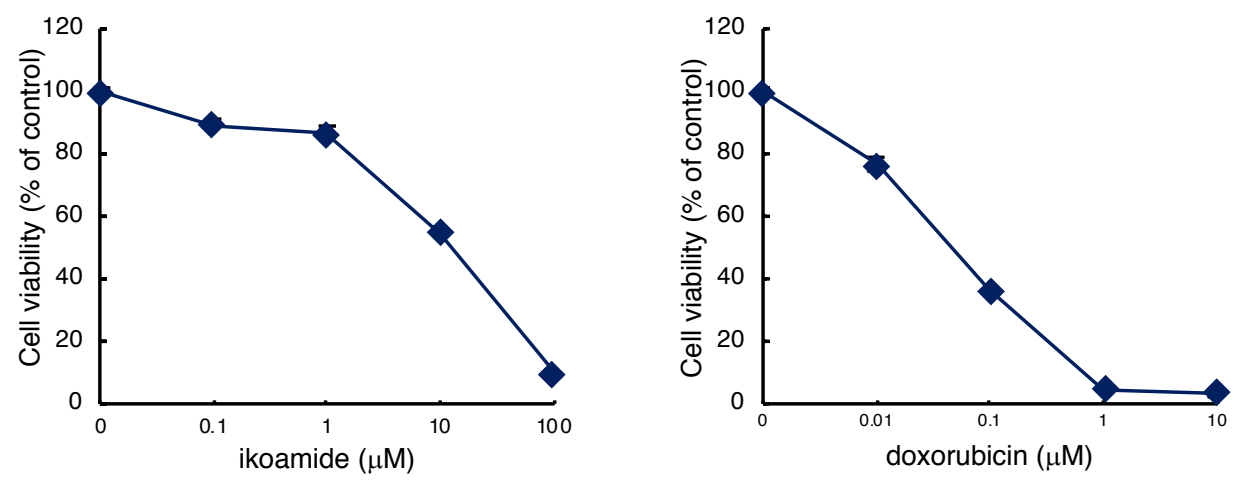

Figure S9. The dose-response curves against HL60 cells $(\mathrm{n}=3)$. 
NMR spectra of ikoamide (1)

abundance

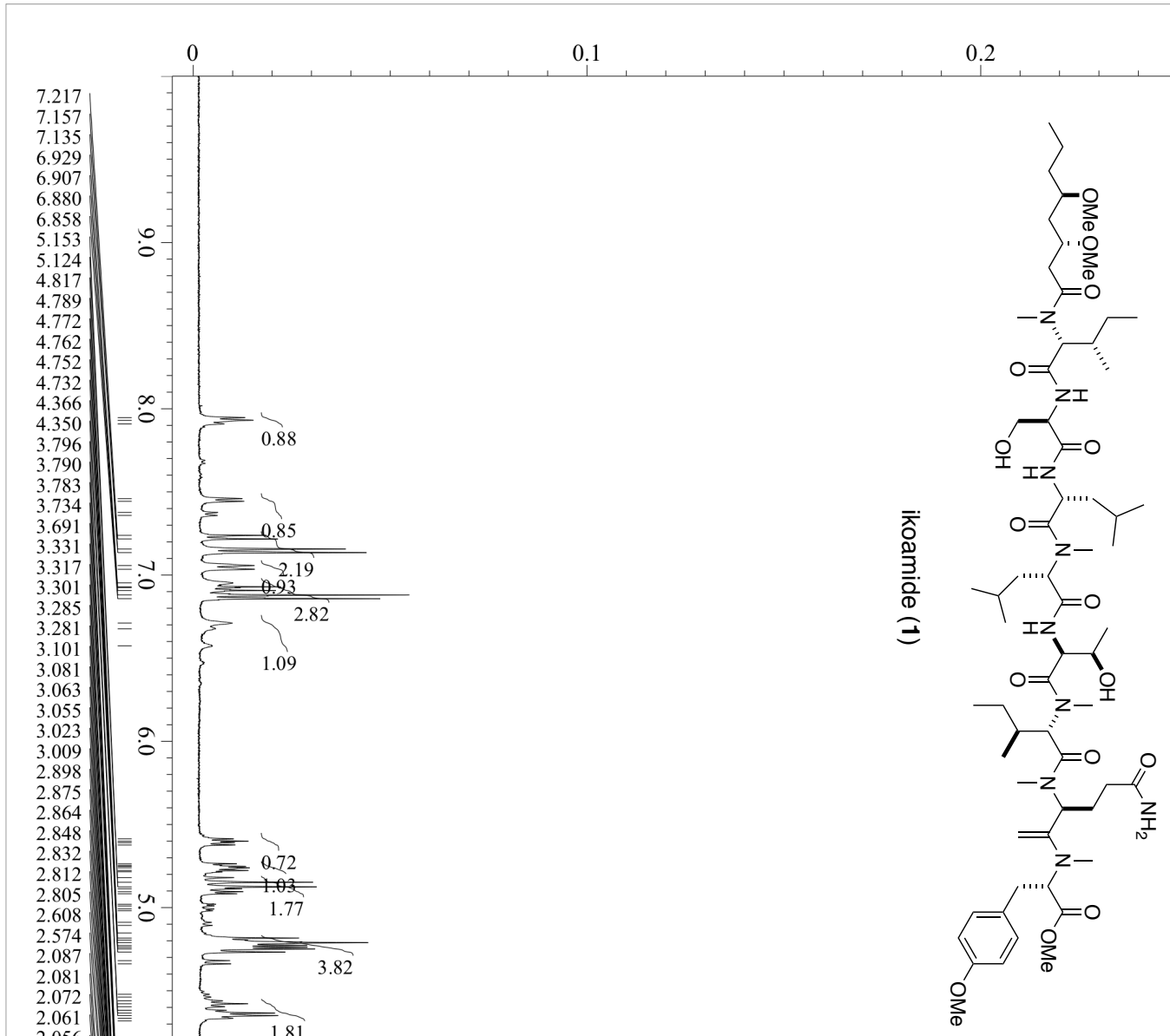

$2.056=1.81$

2.050 )

2.039
1.715

1.715 )

594

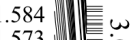

1.573 Wh

1.551

$1.542 \mathrm{~m}=$

1.526

1.510
1.489

1.471 稁 $N$

1.360 W

$\left.\begin{array}{l}1.342 \\ 1.323 \\ 1.305\end{array}\right)$

1.323
1.305

1.144

1.128
1.114
1.098

$1.114 \sqrt{1.098}$

0.982 -

0.974 疟 0

0.966

$0.957 /$

$\times 0.946$

. 0.929

亚 0.910

के 0.903

Ф 0.884

$\stackrel{9}{0.884}$

定 0.860

严 0.844

응 0.796

$\because 0.791$

㱐 0.779

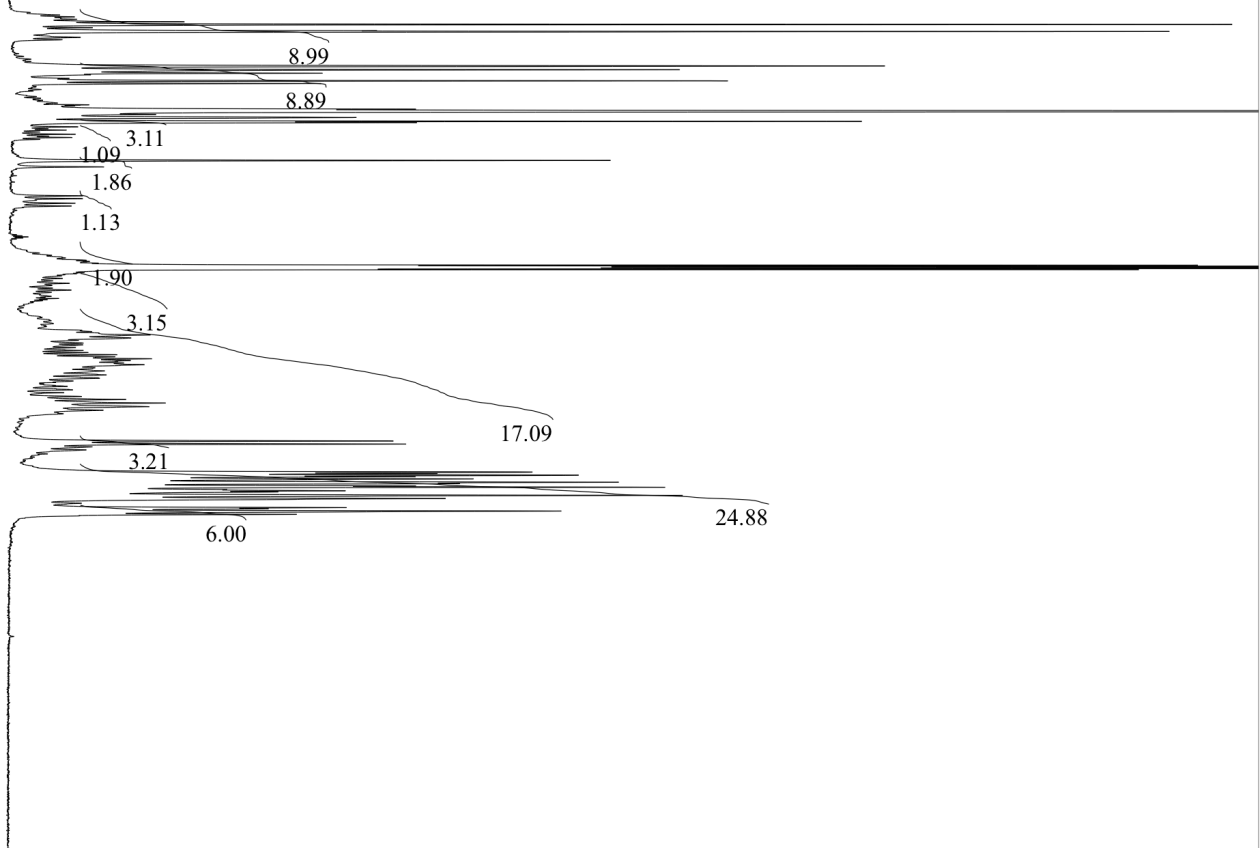




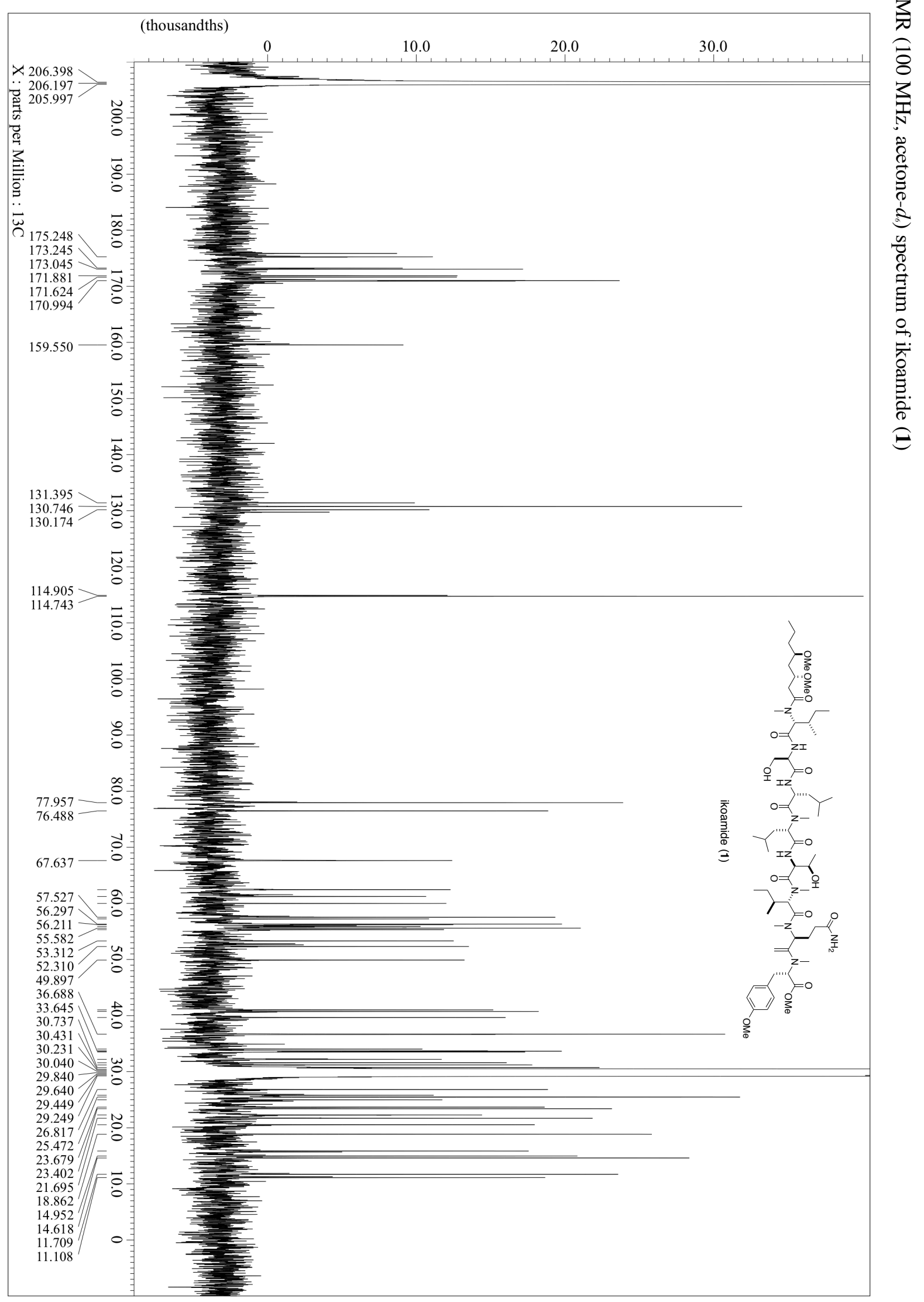




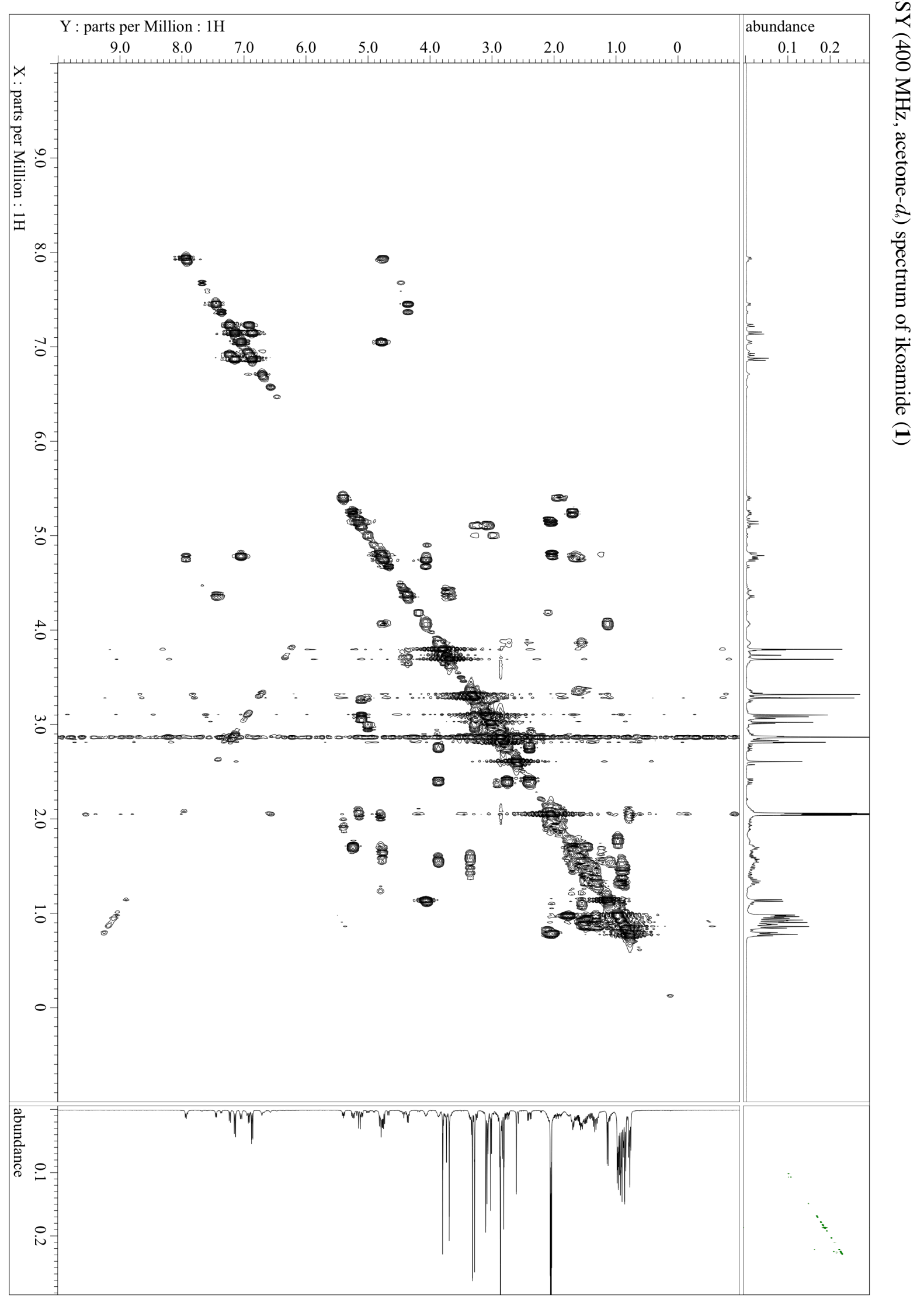




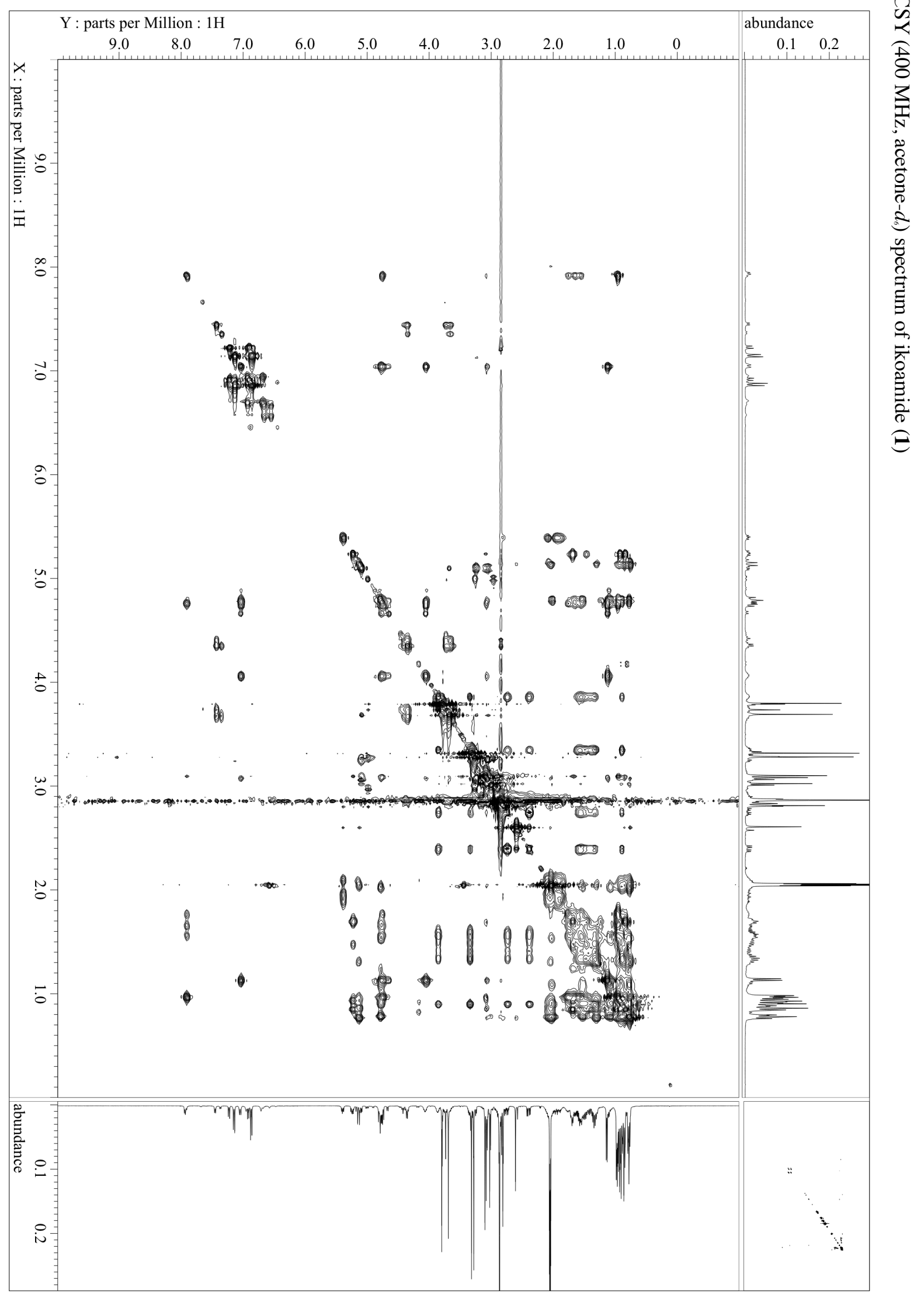




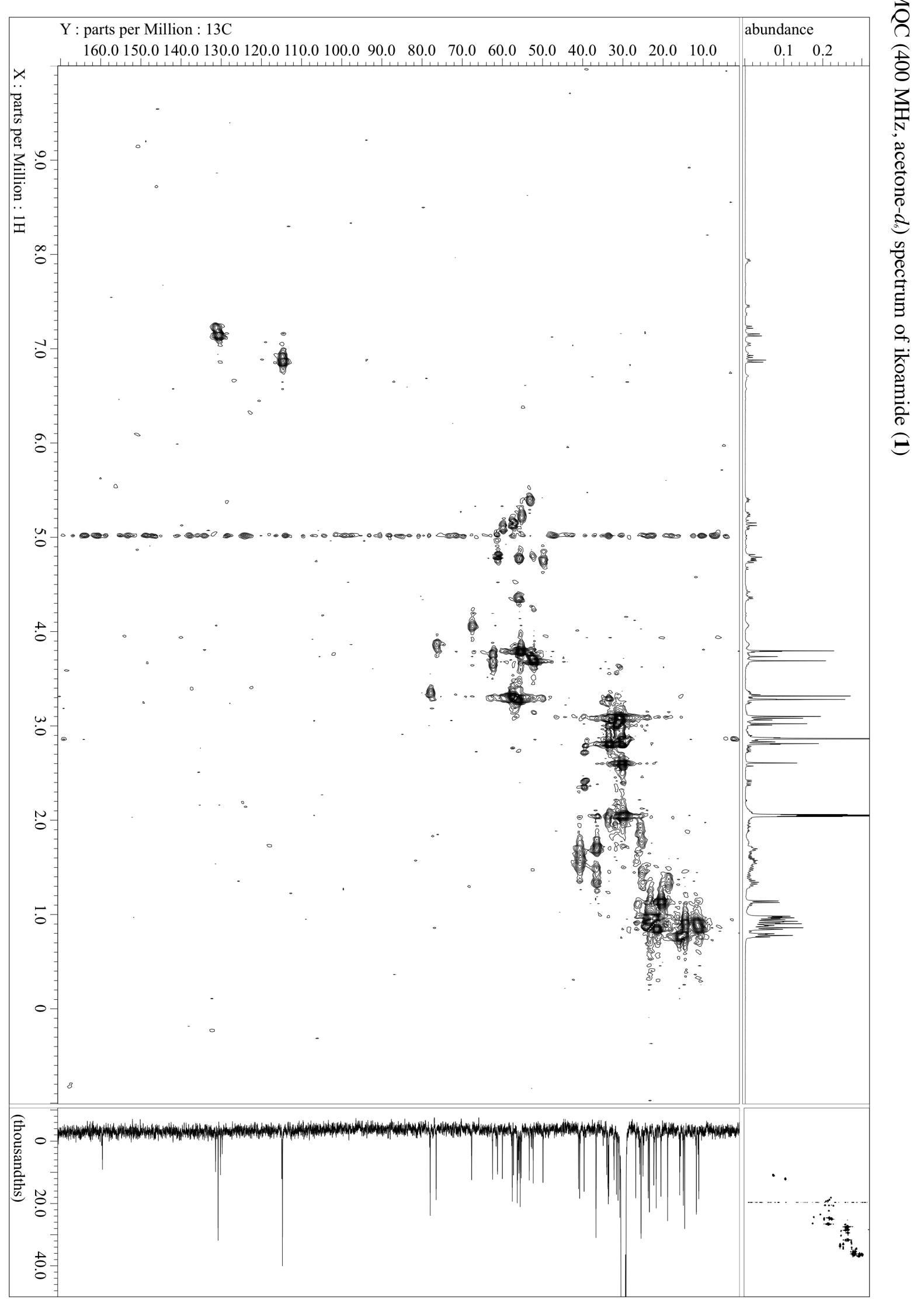




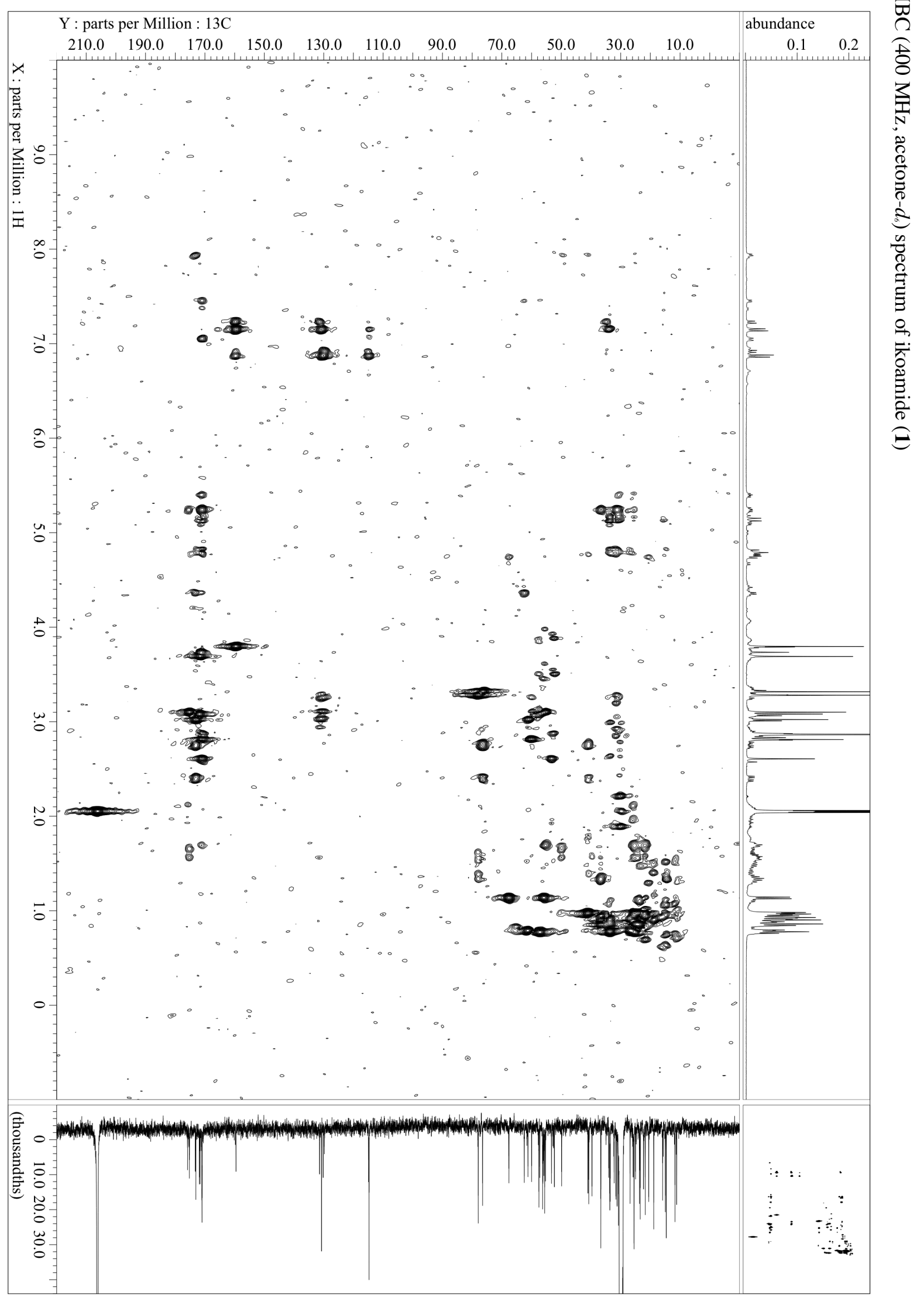




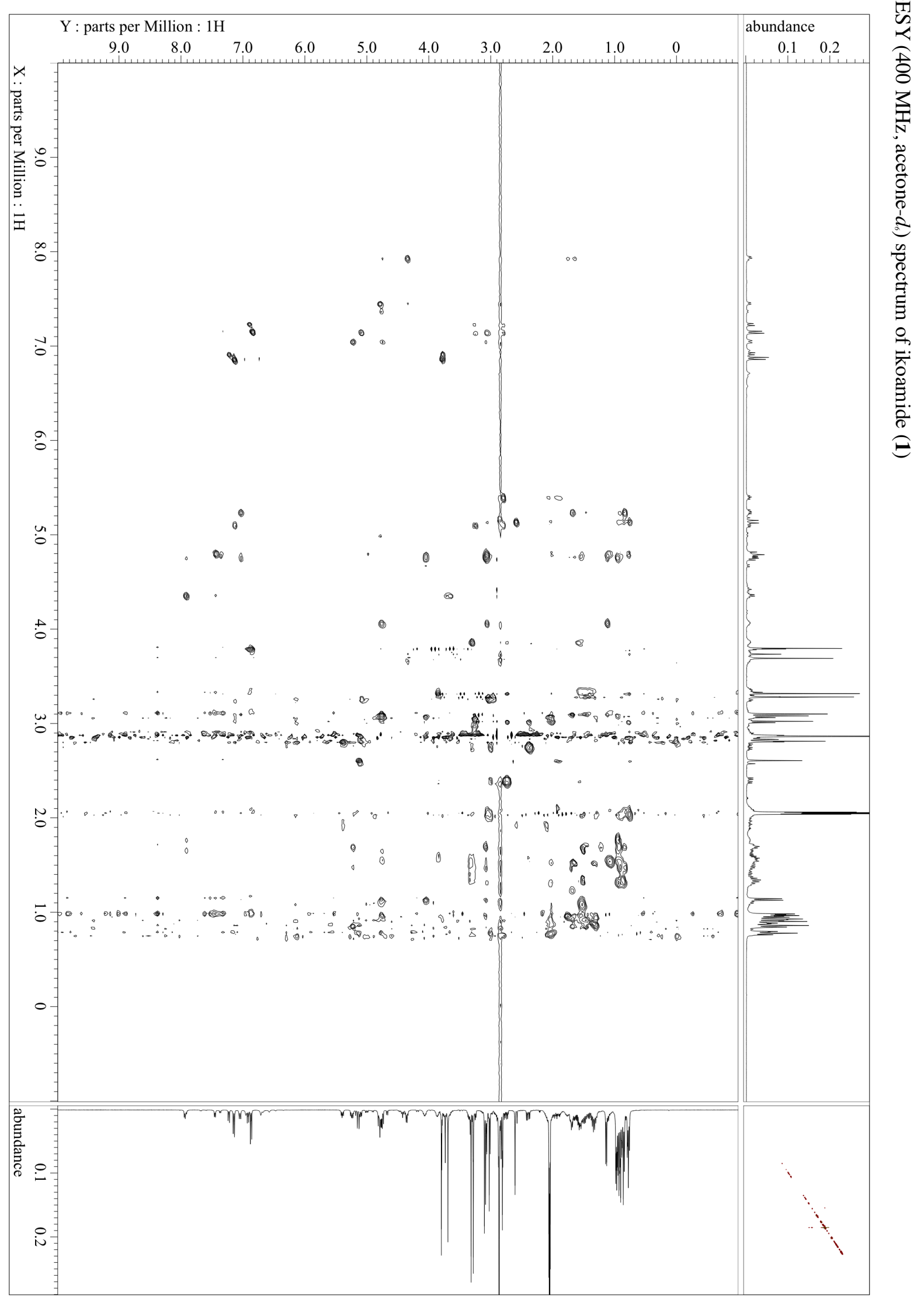




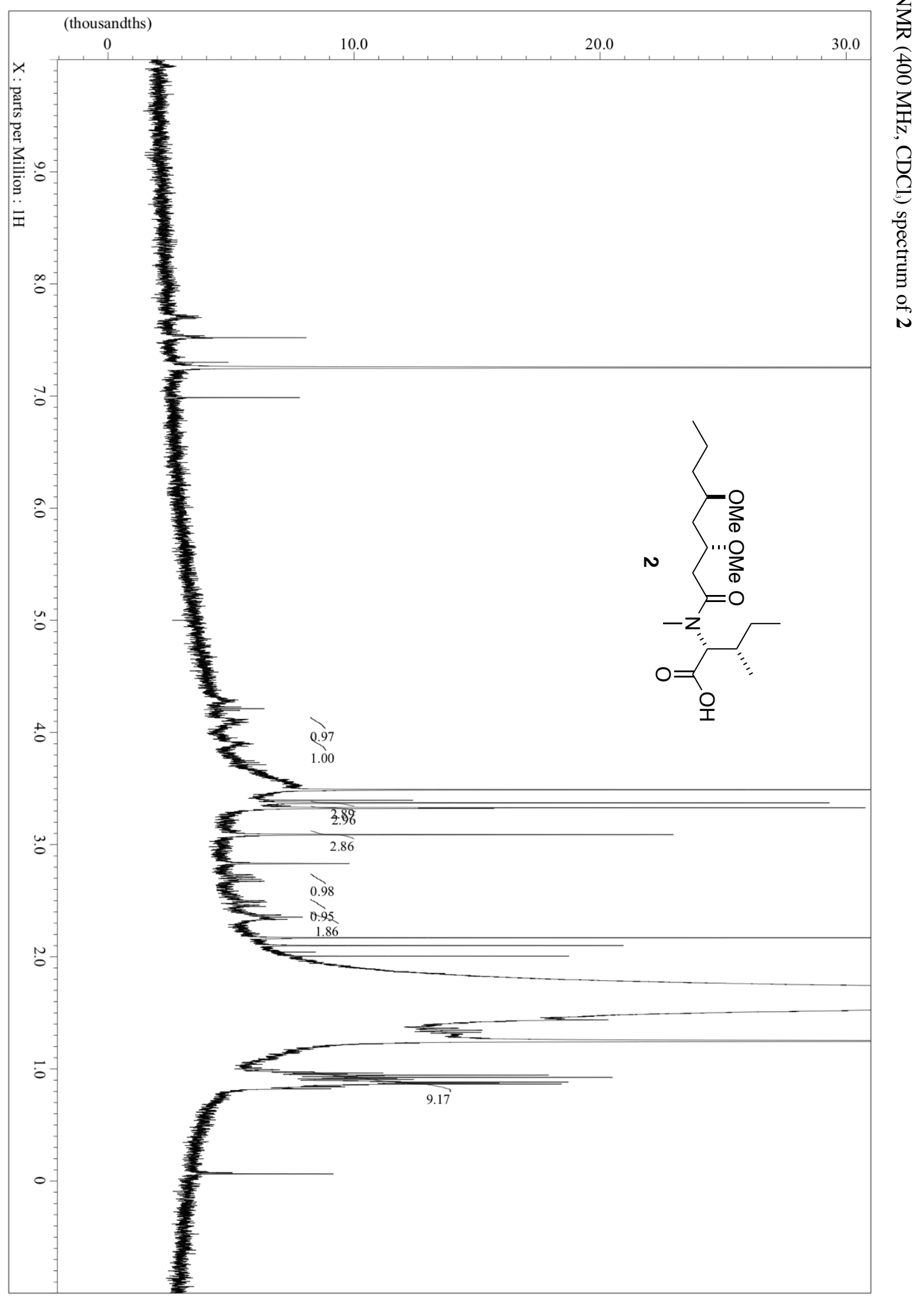




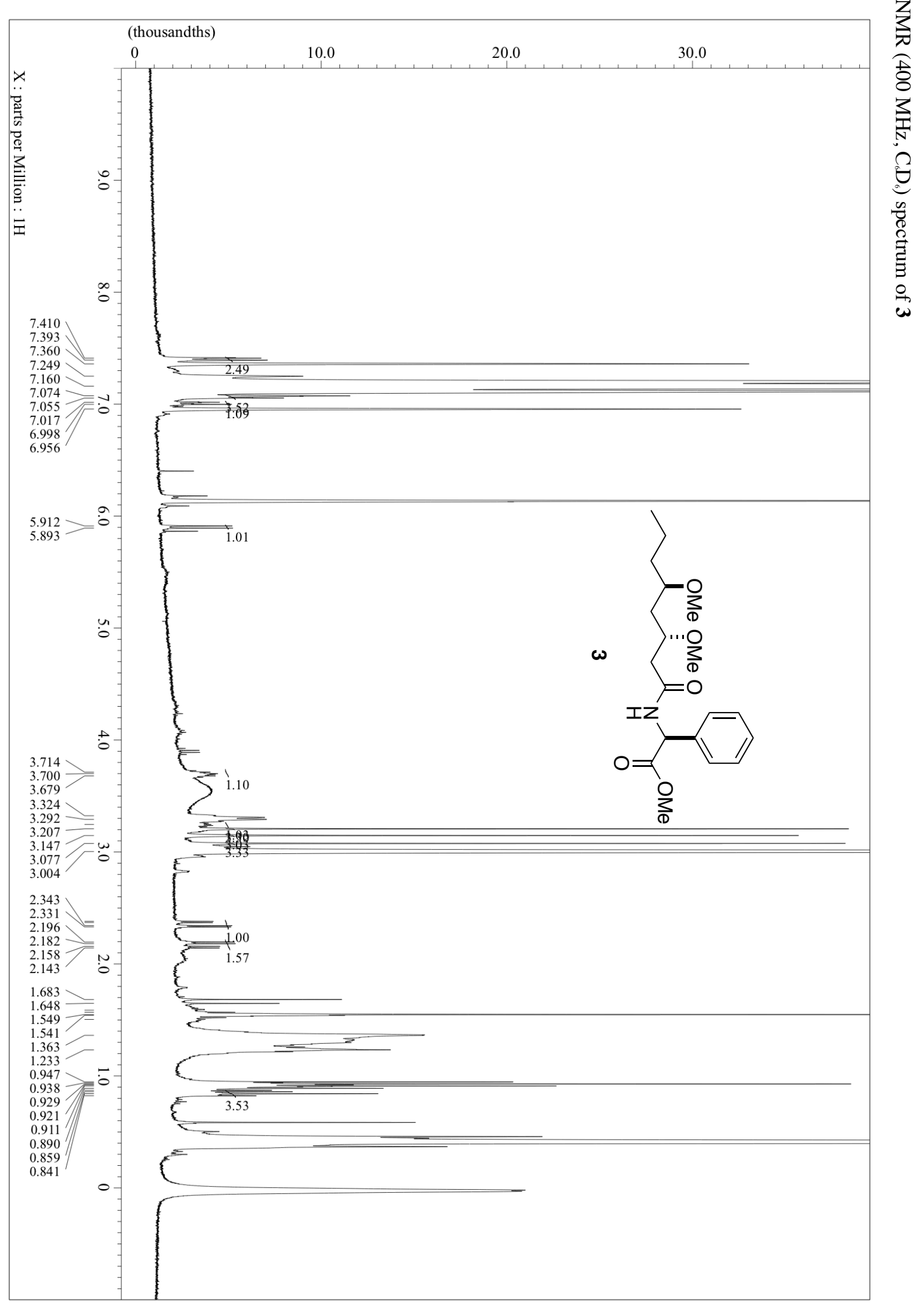




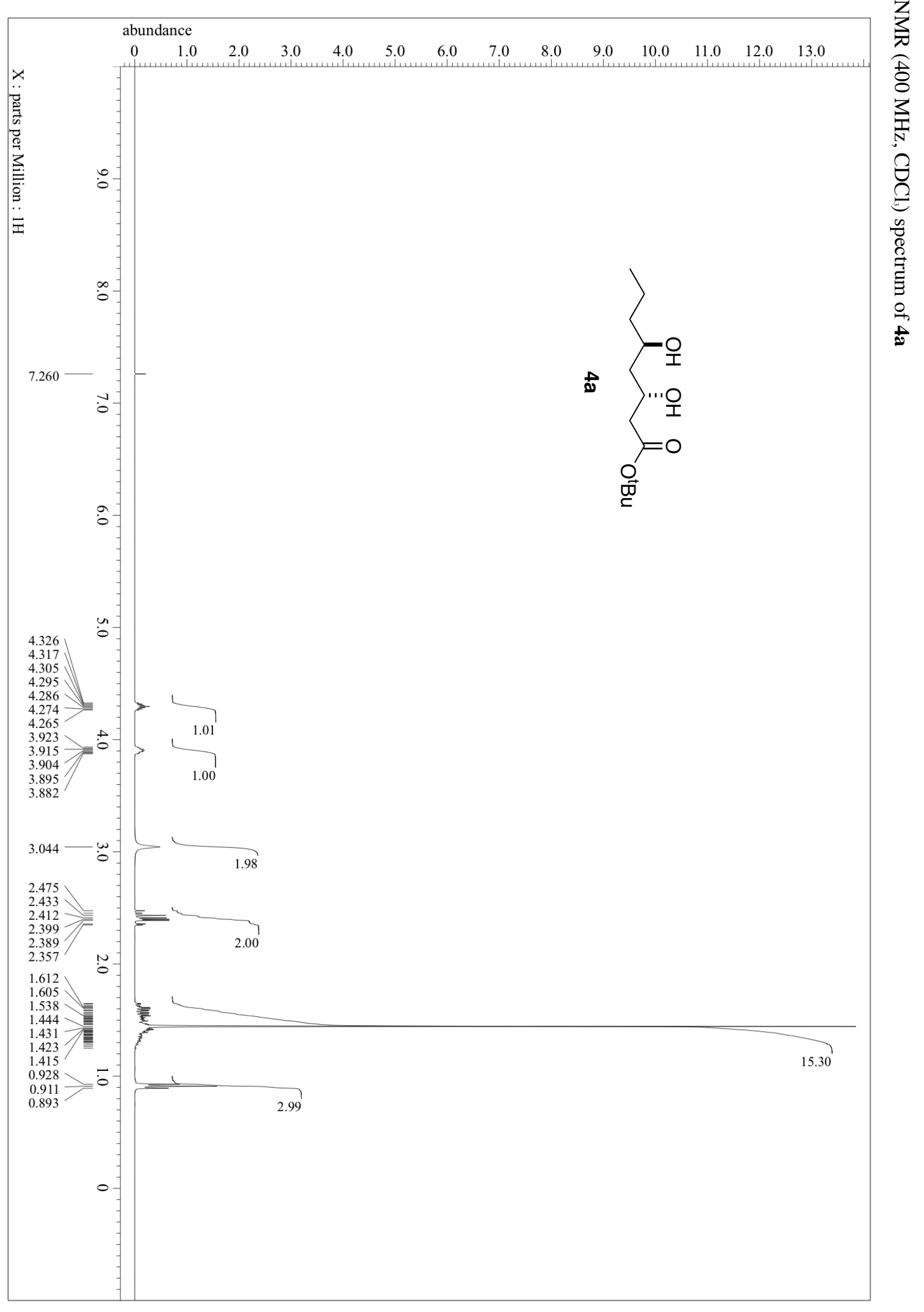




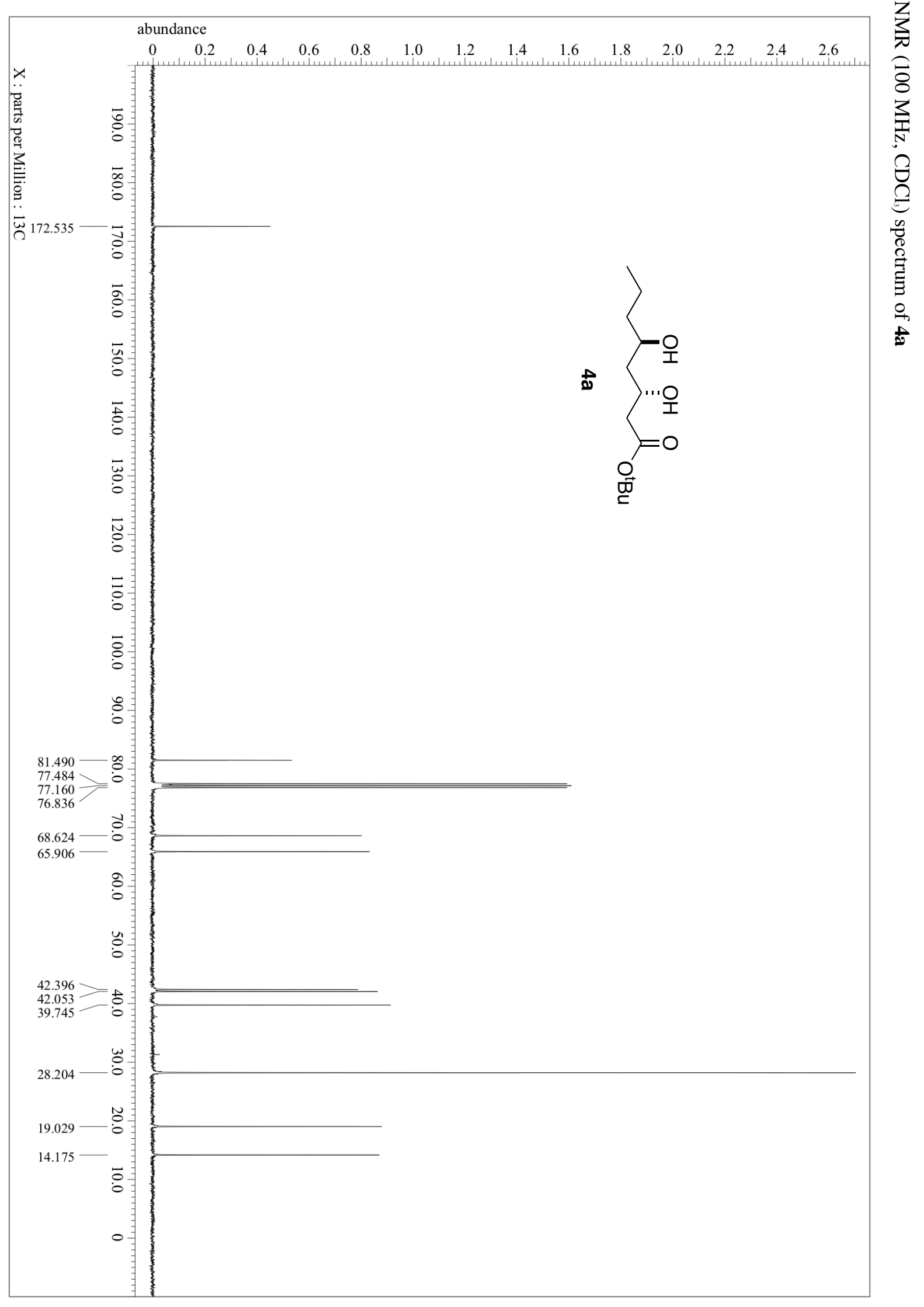




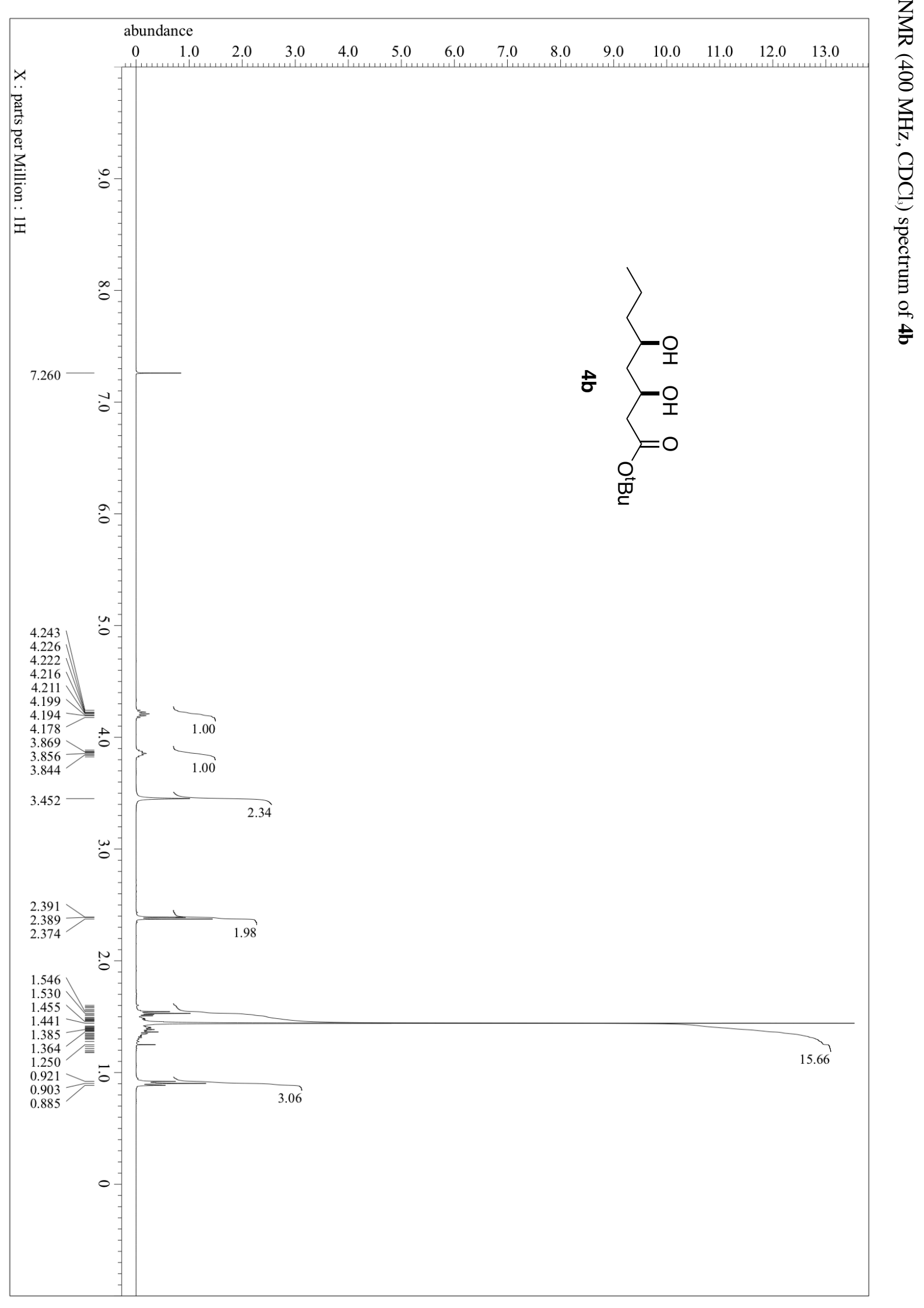




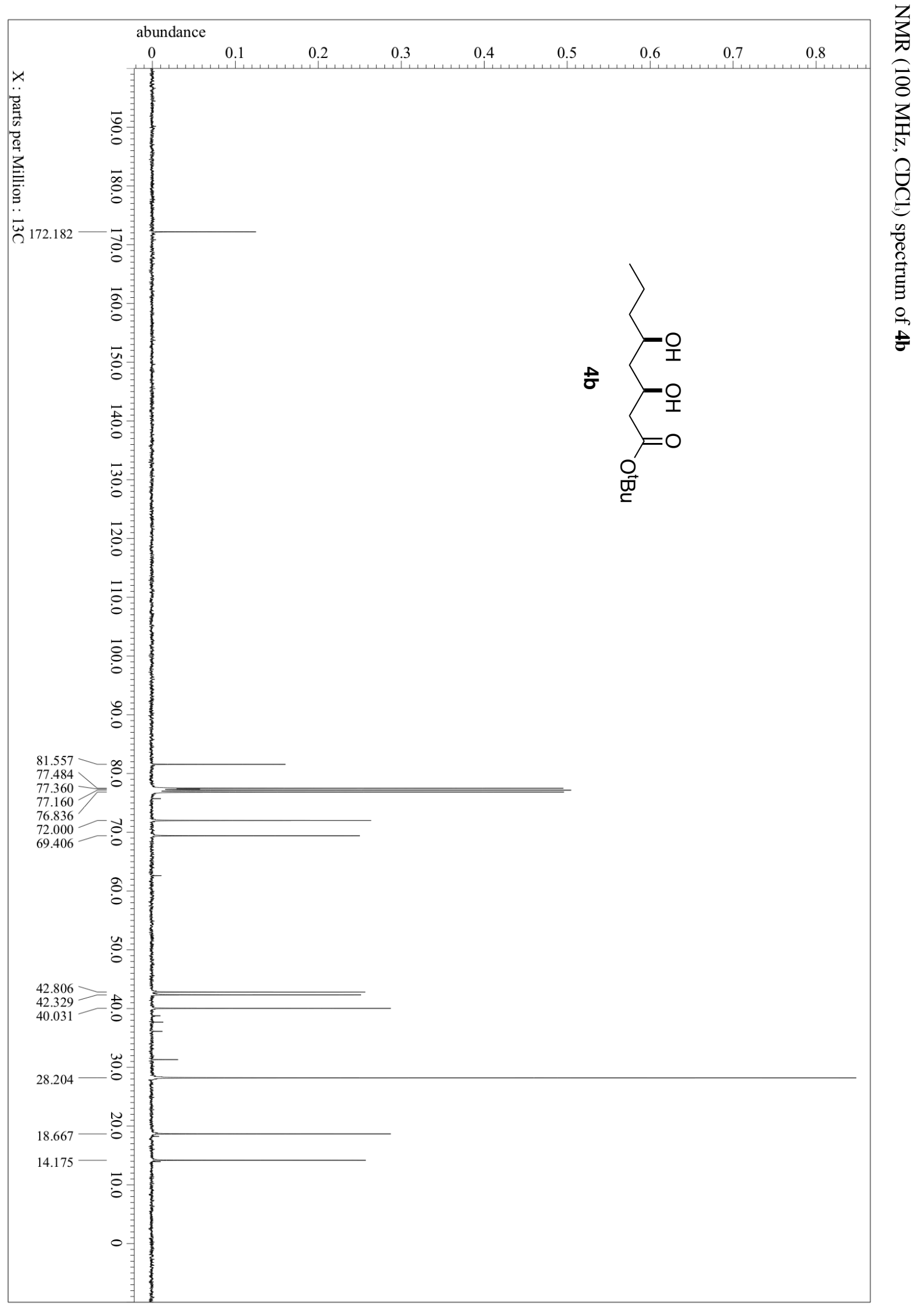




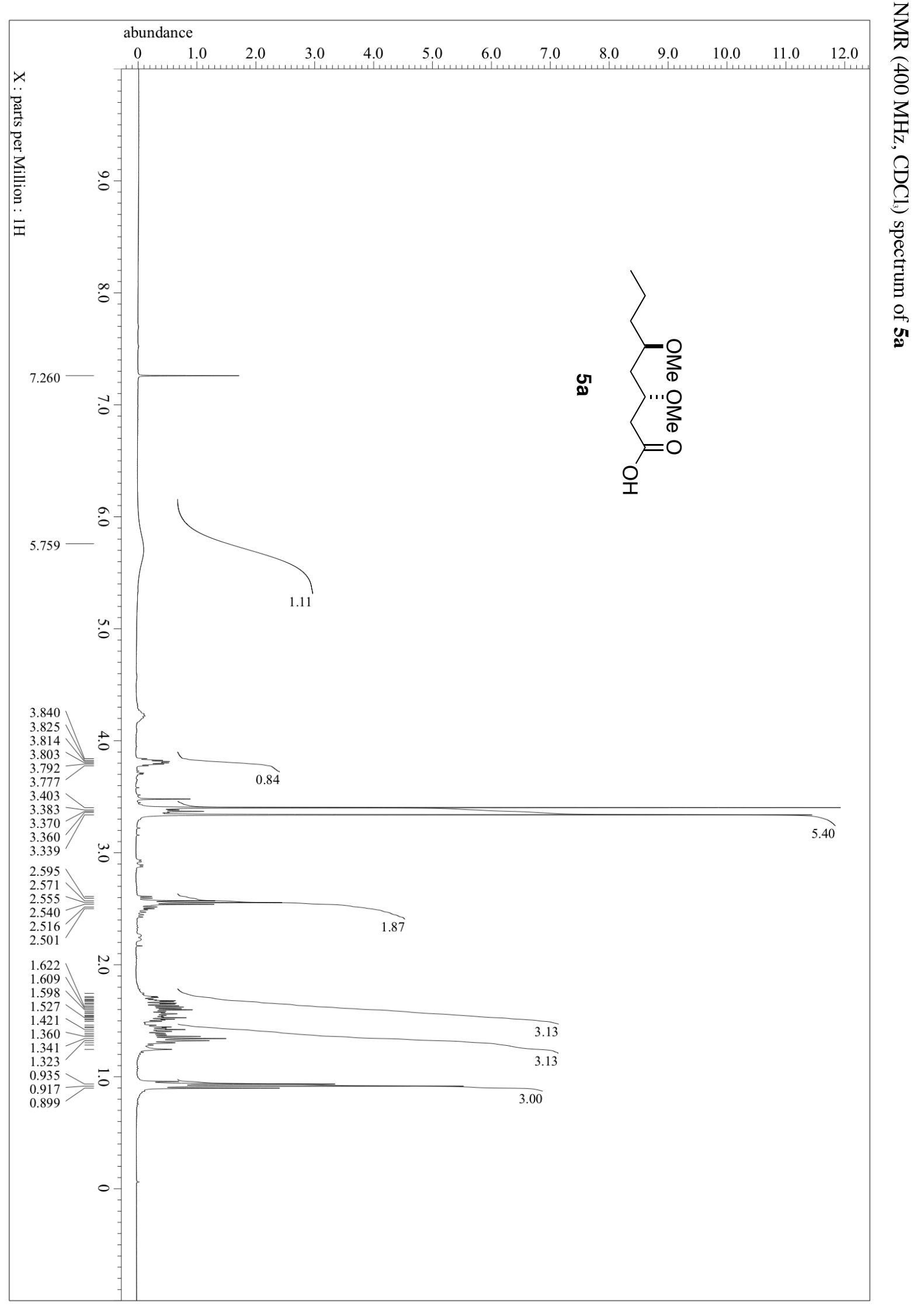




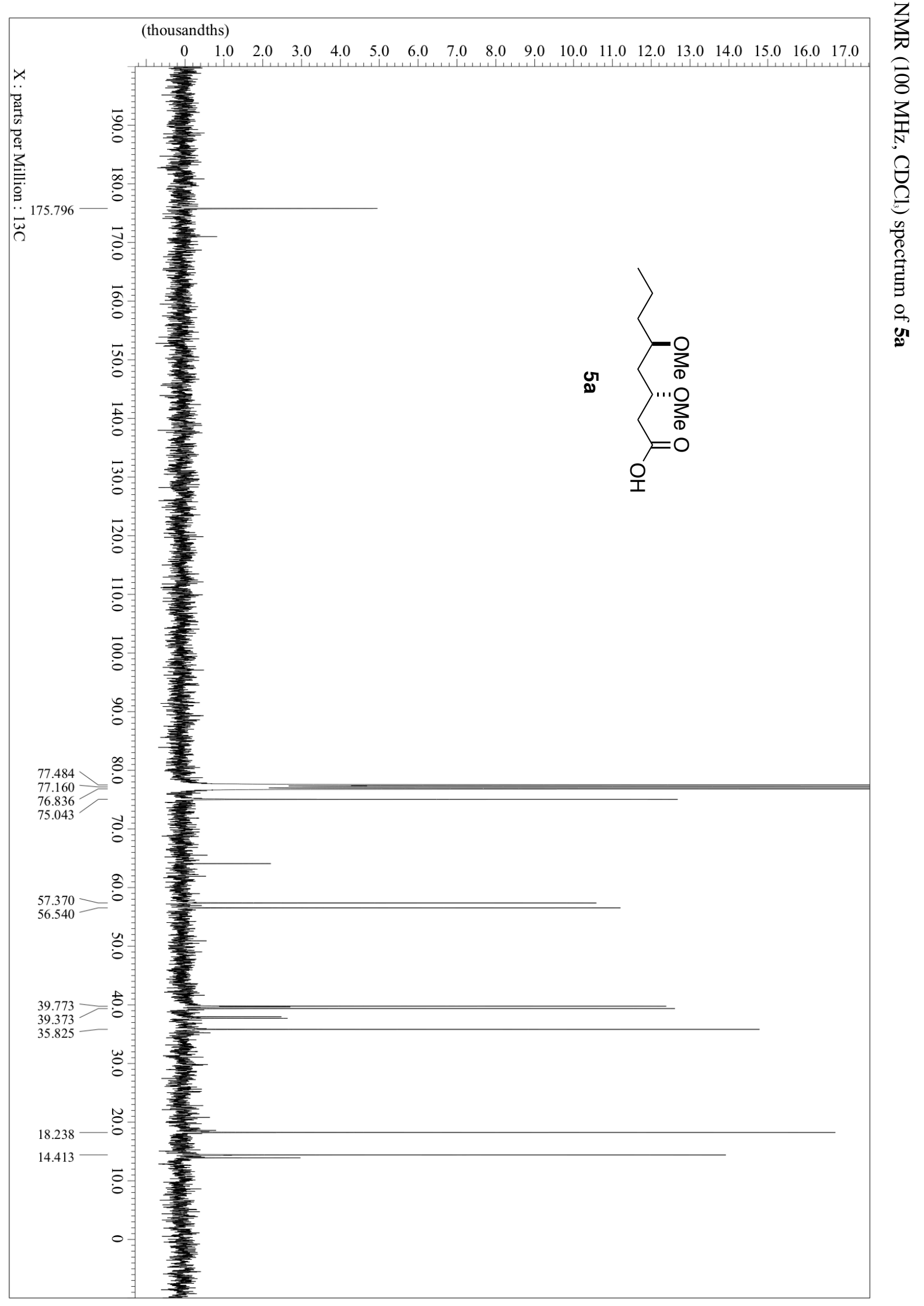




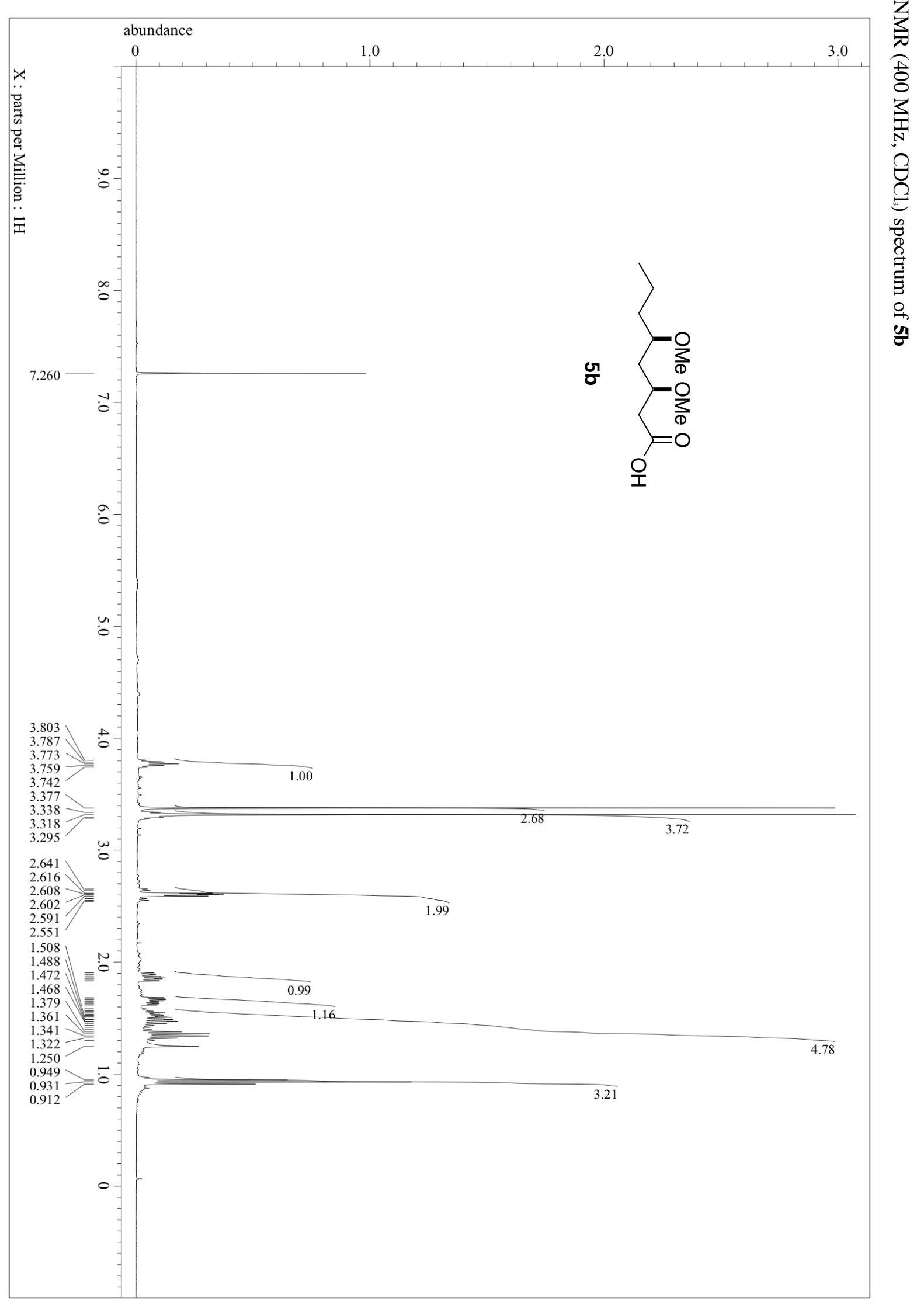




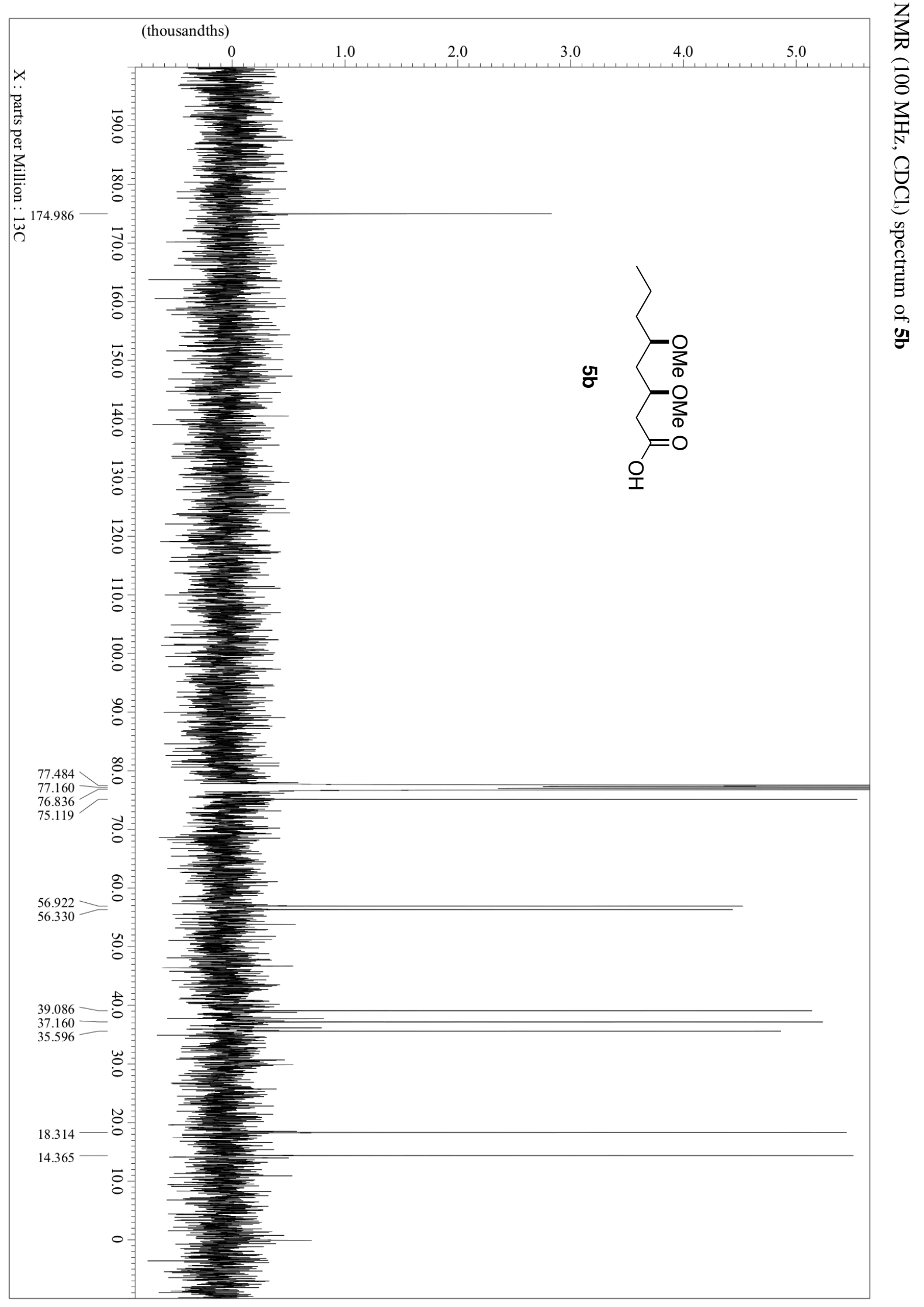




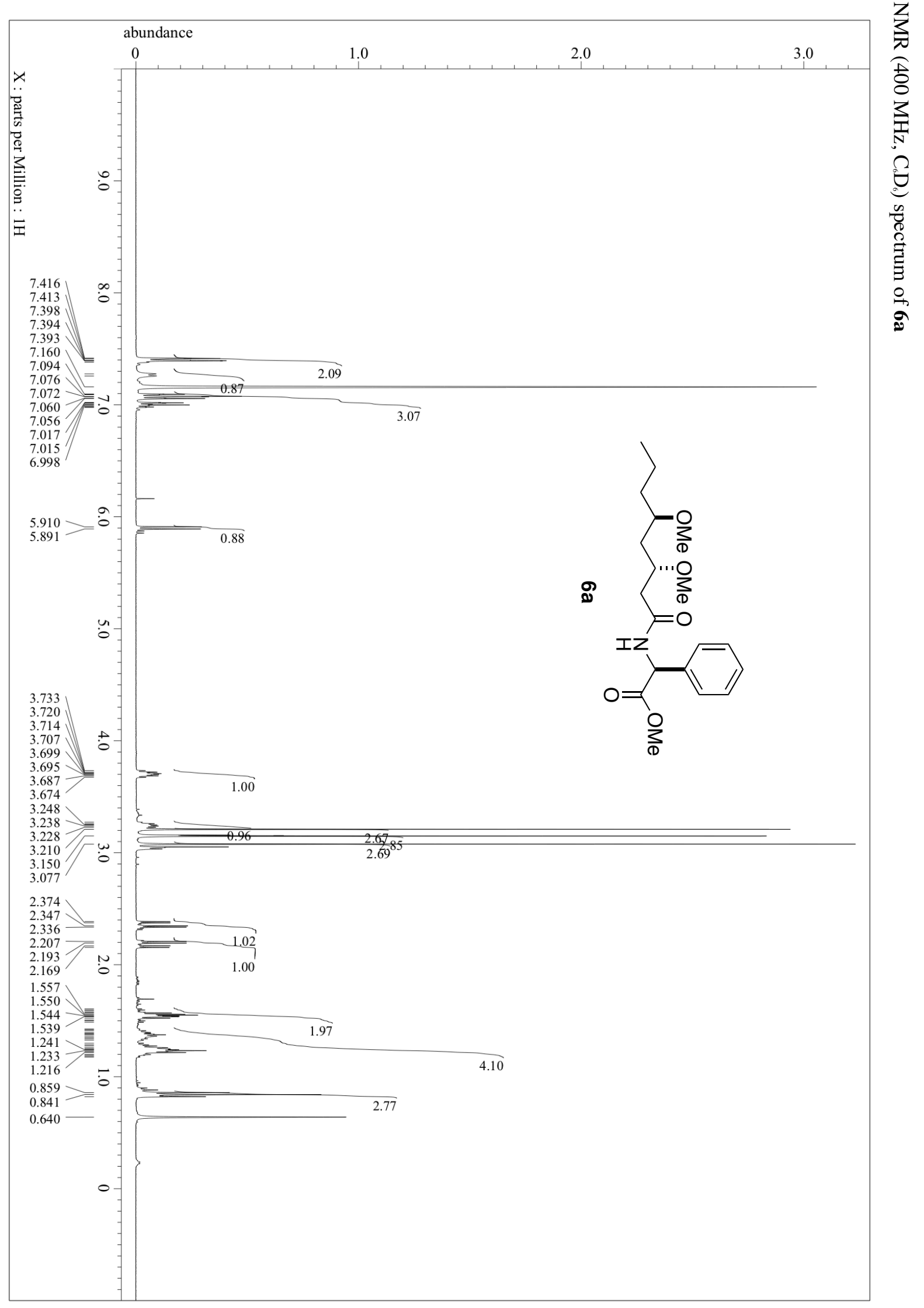




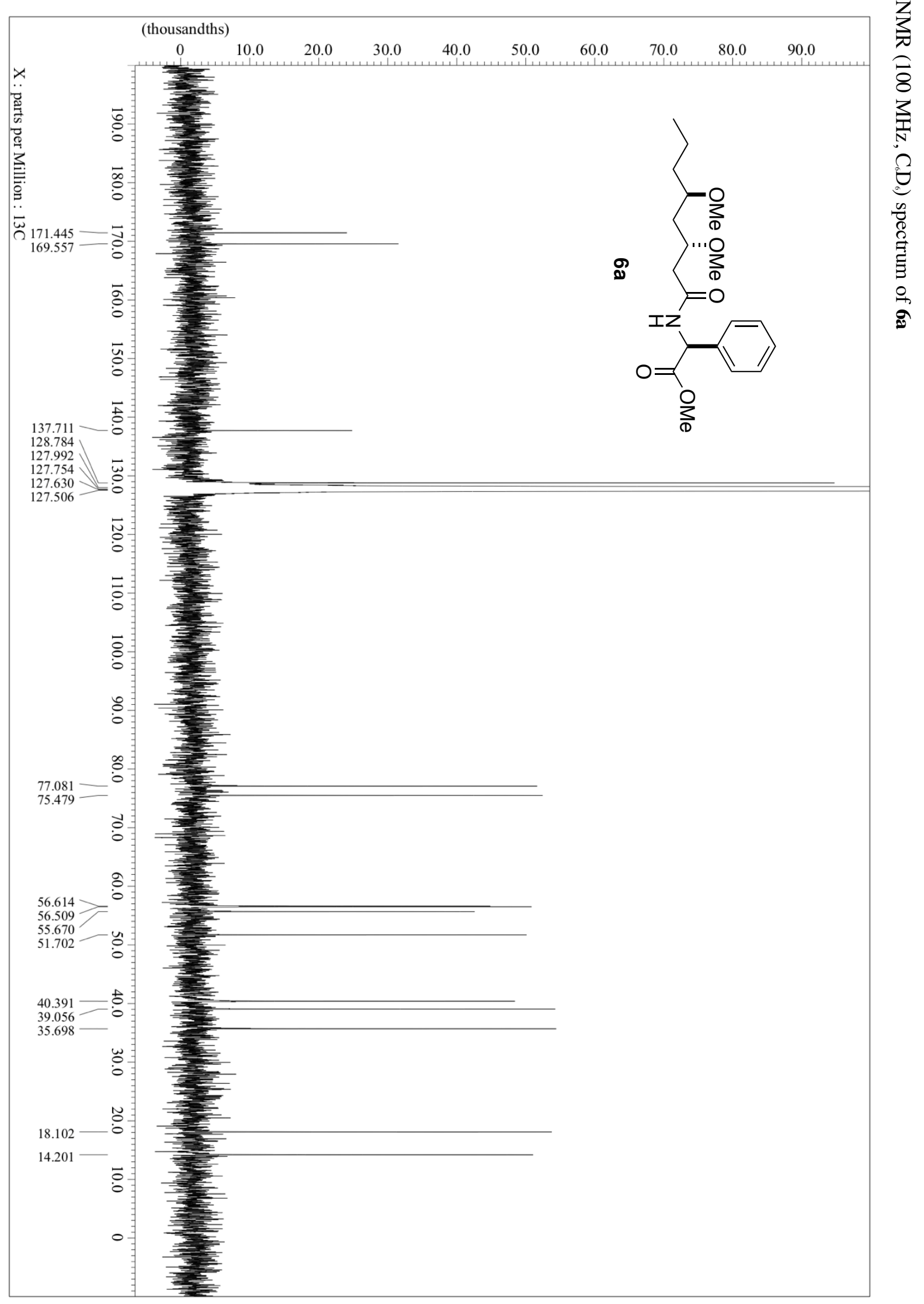




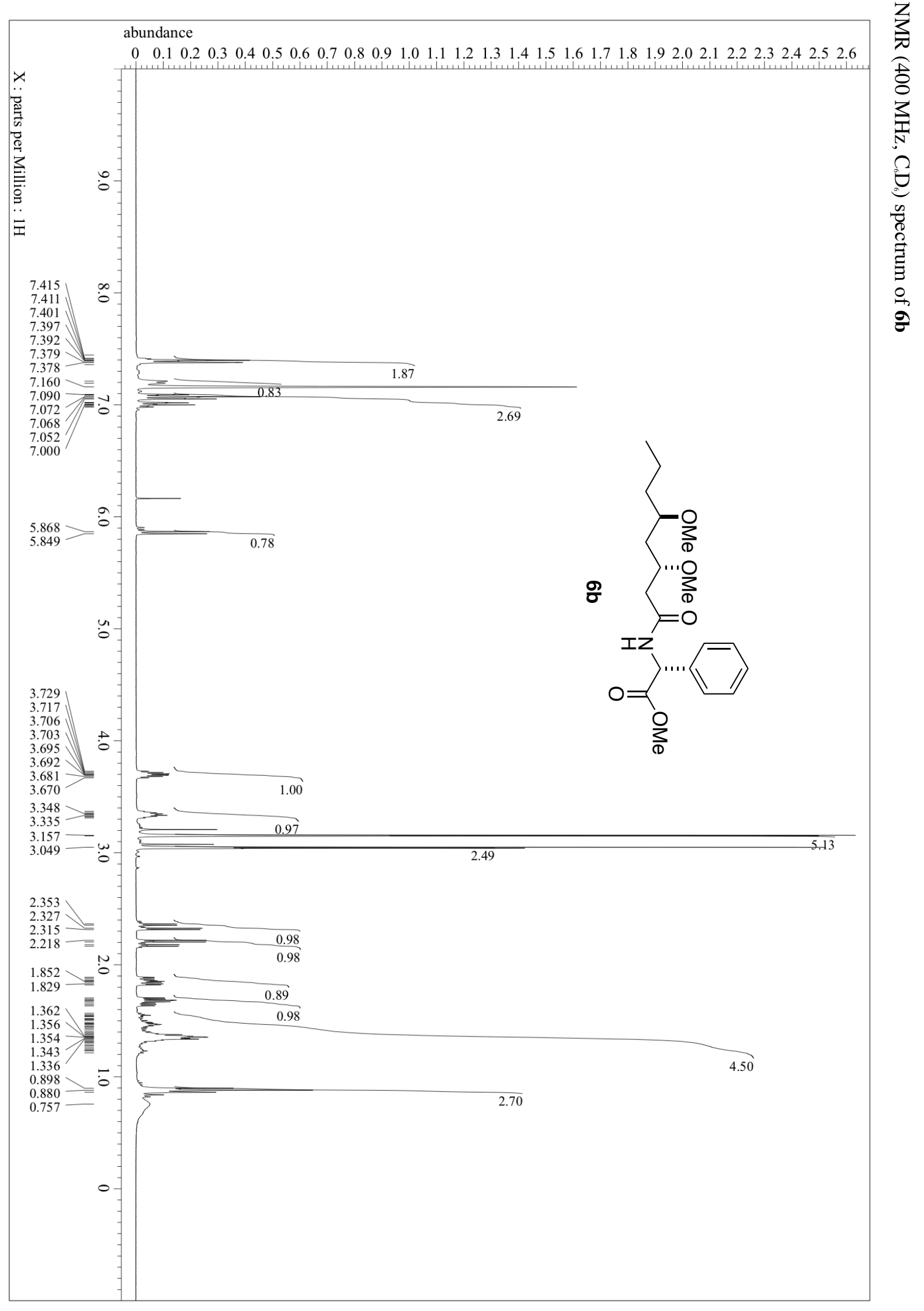




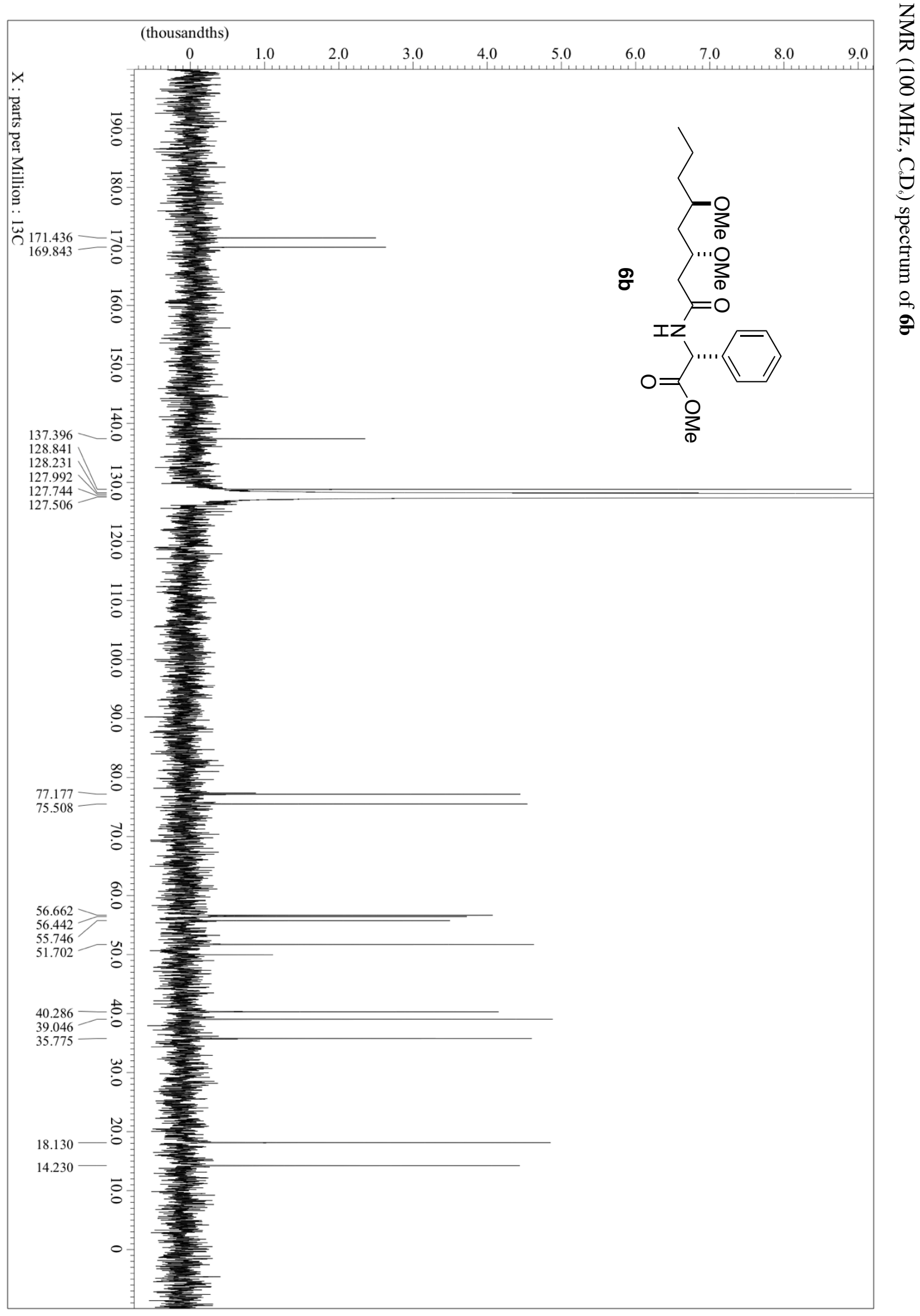




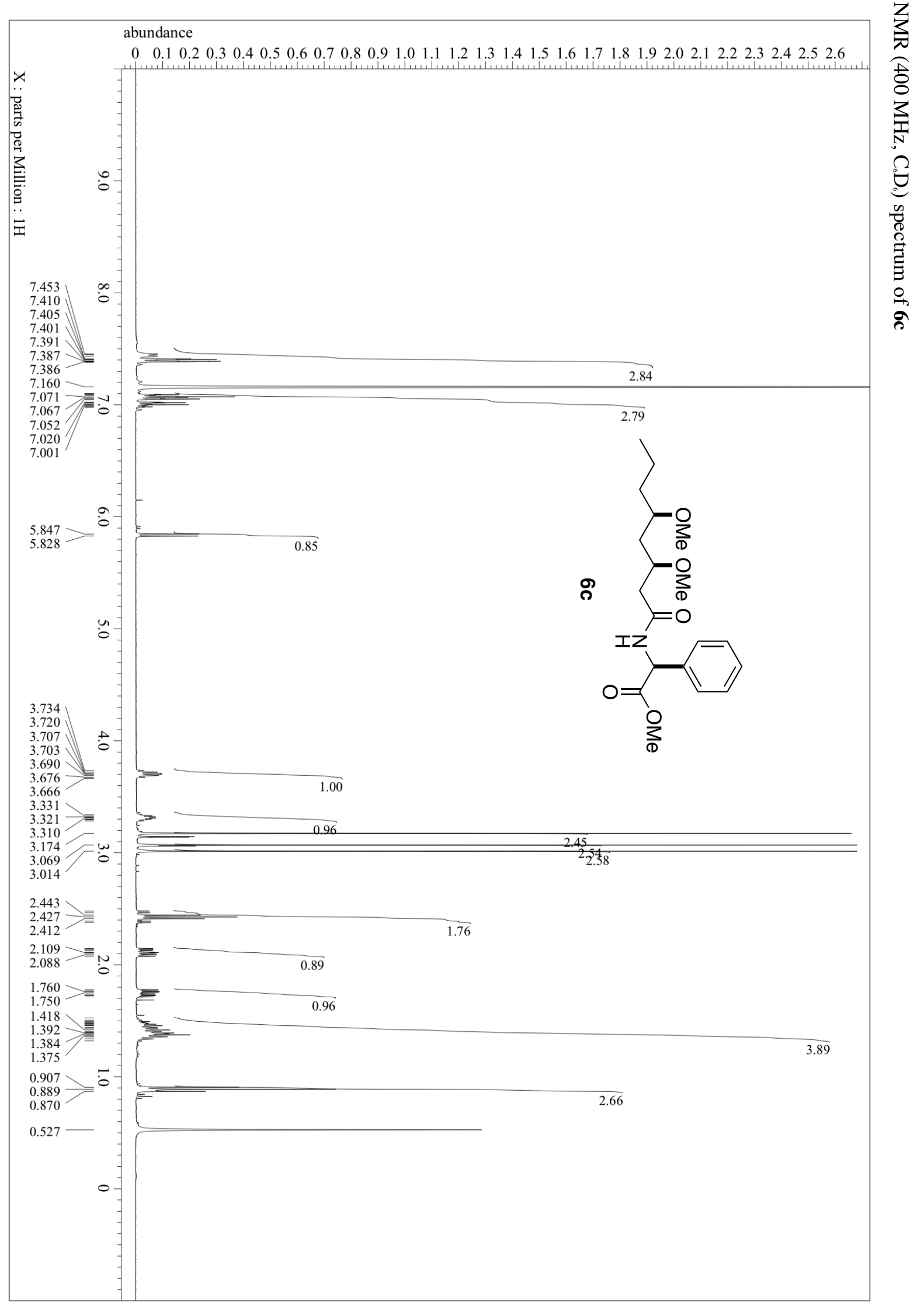




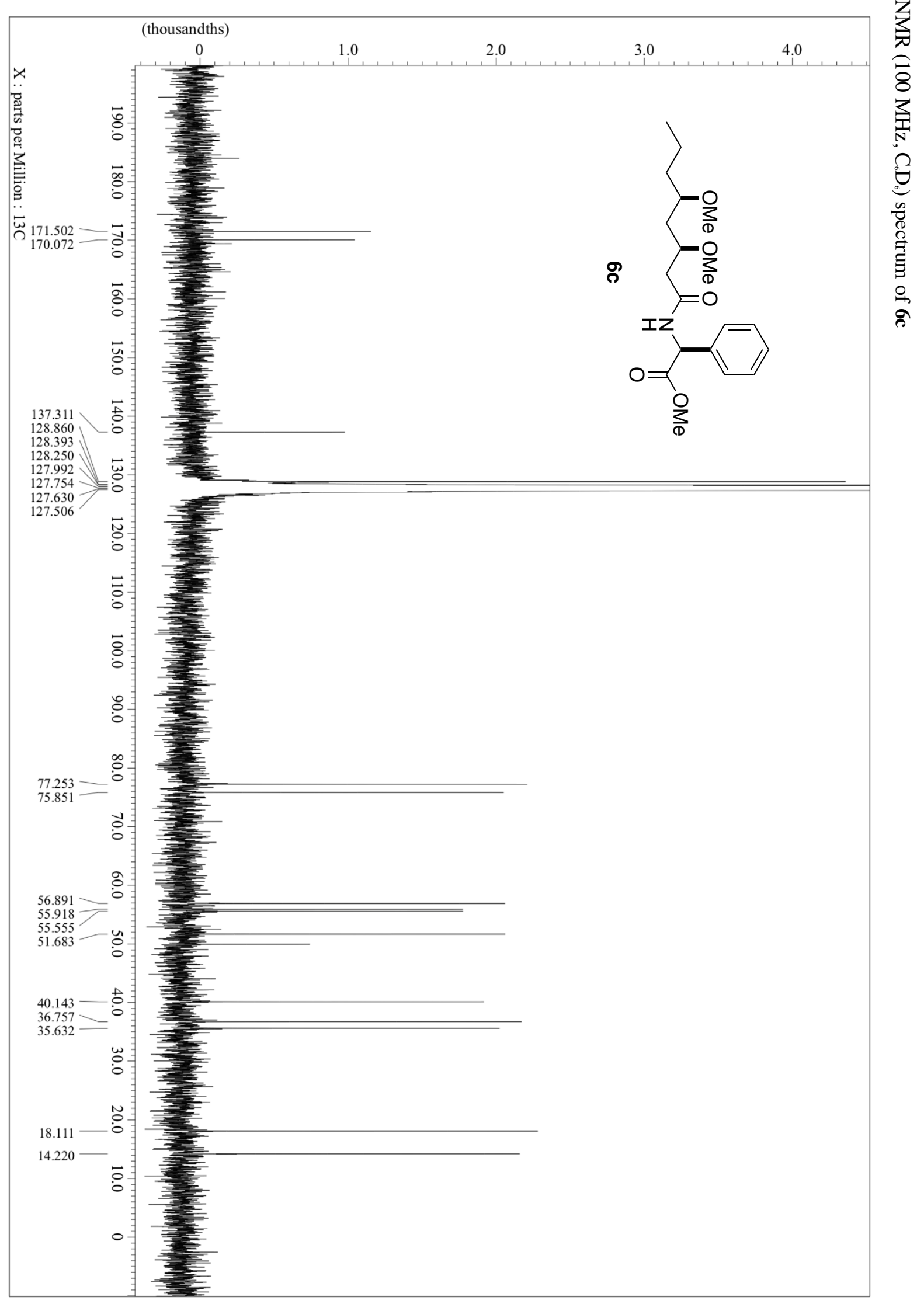




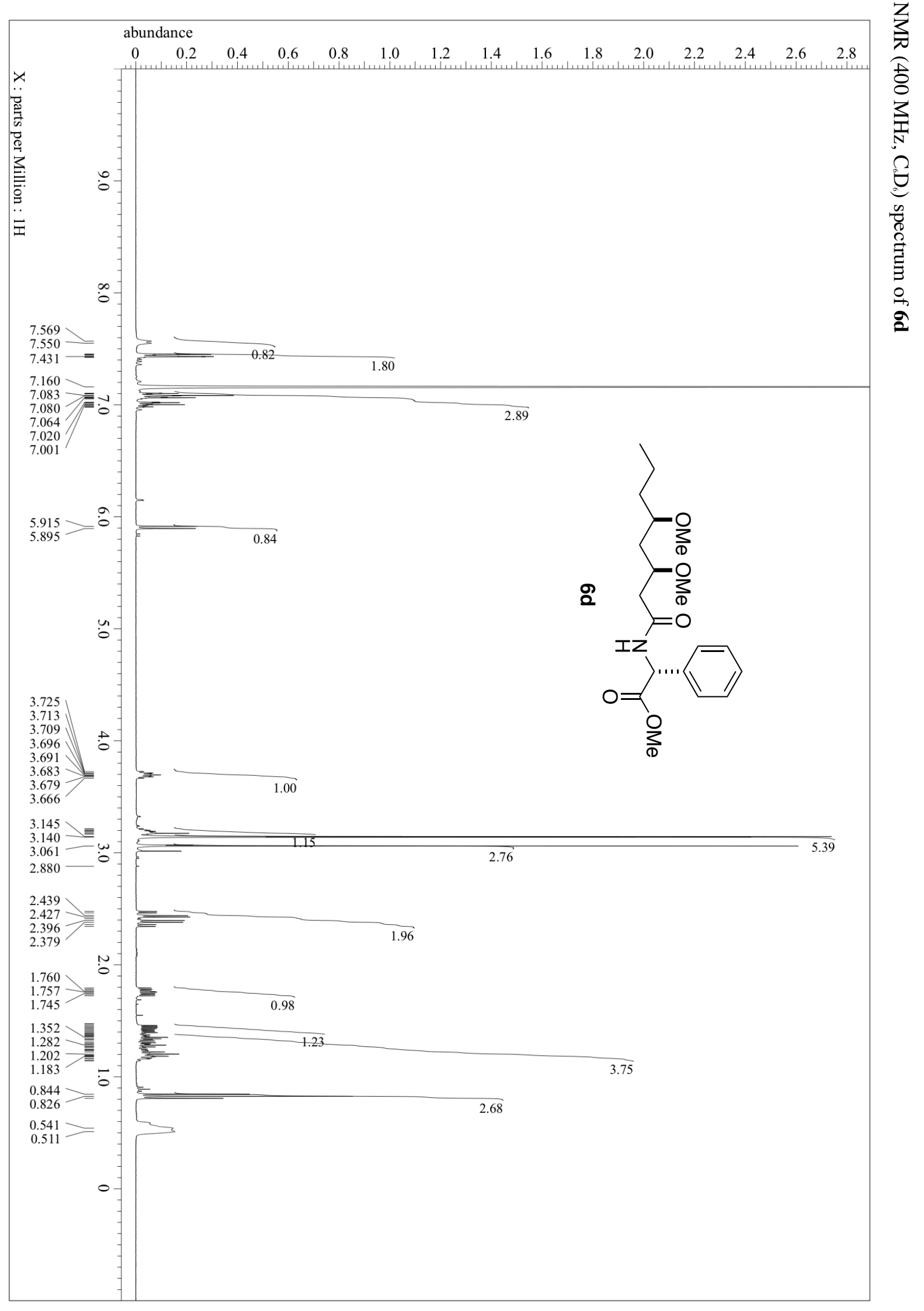




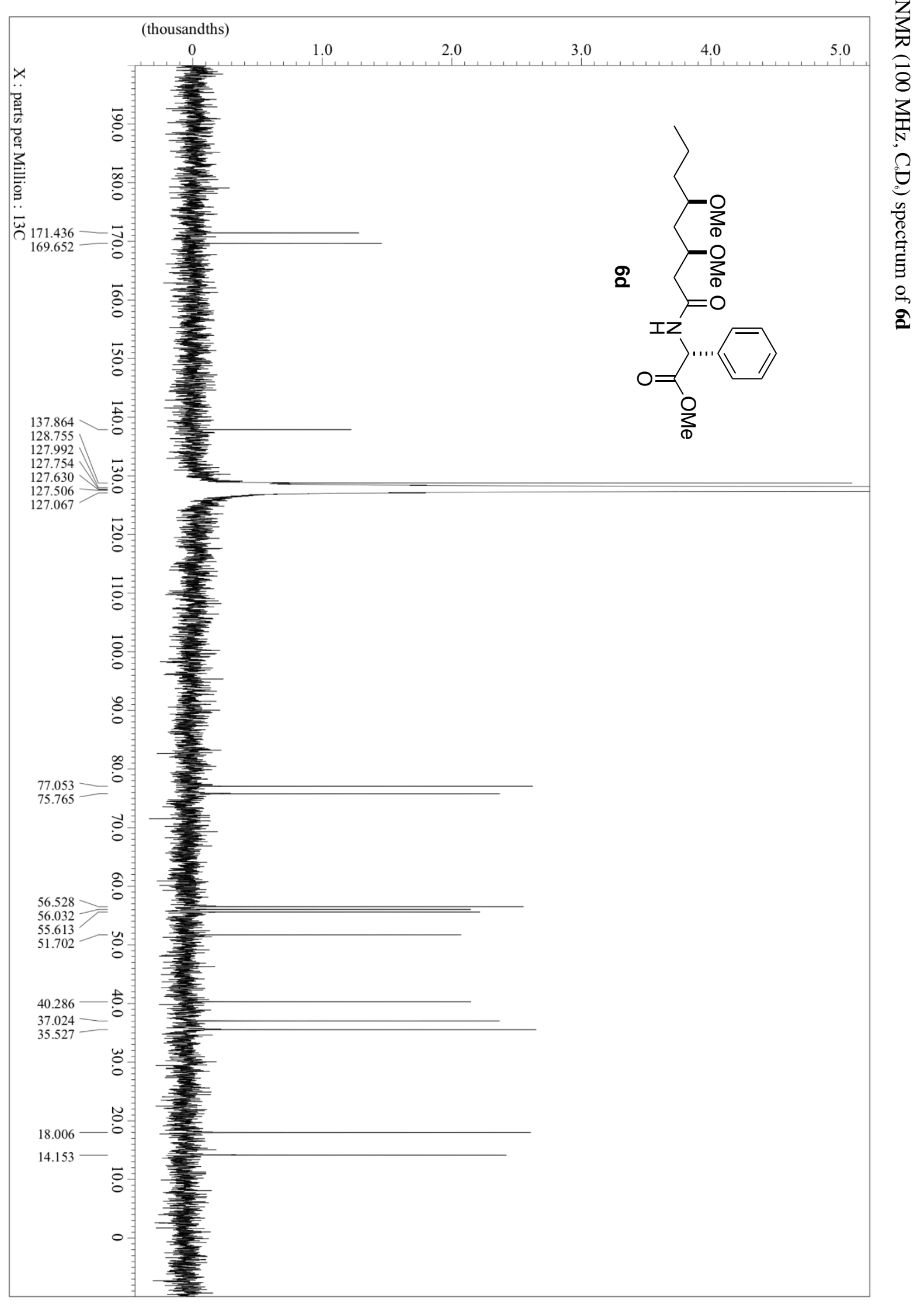




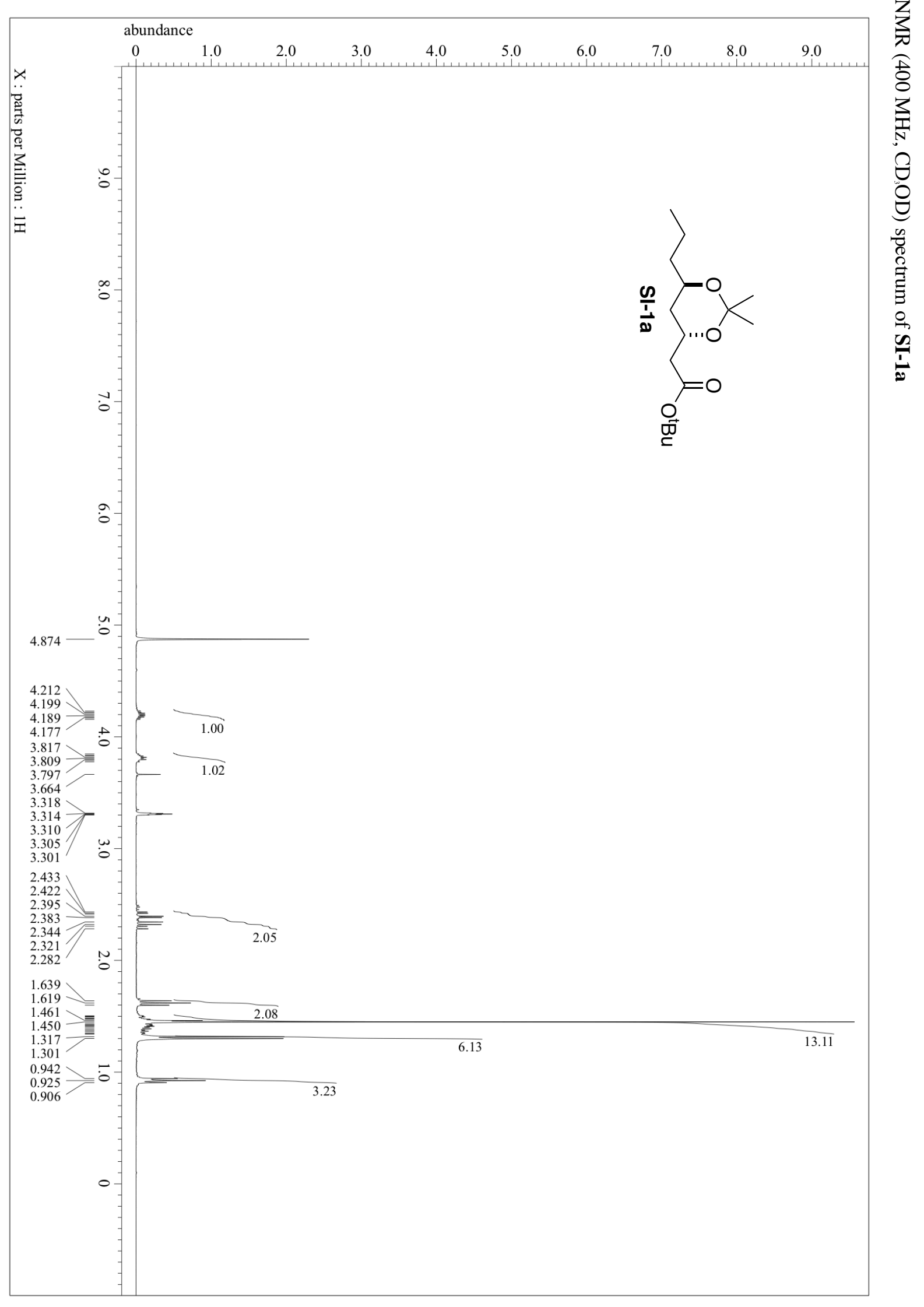




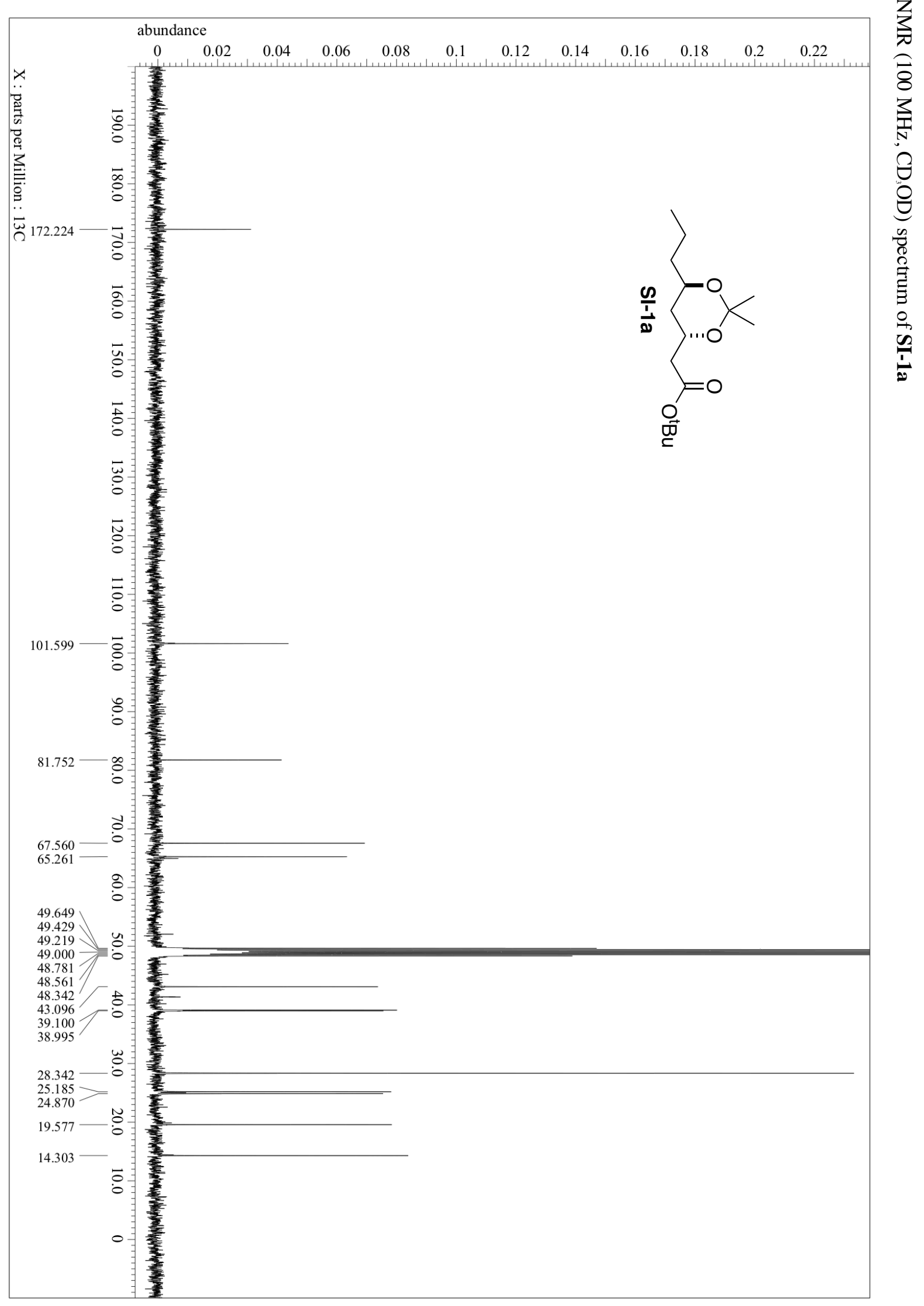




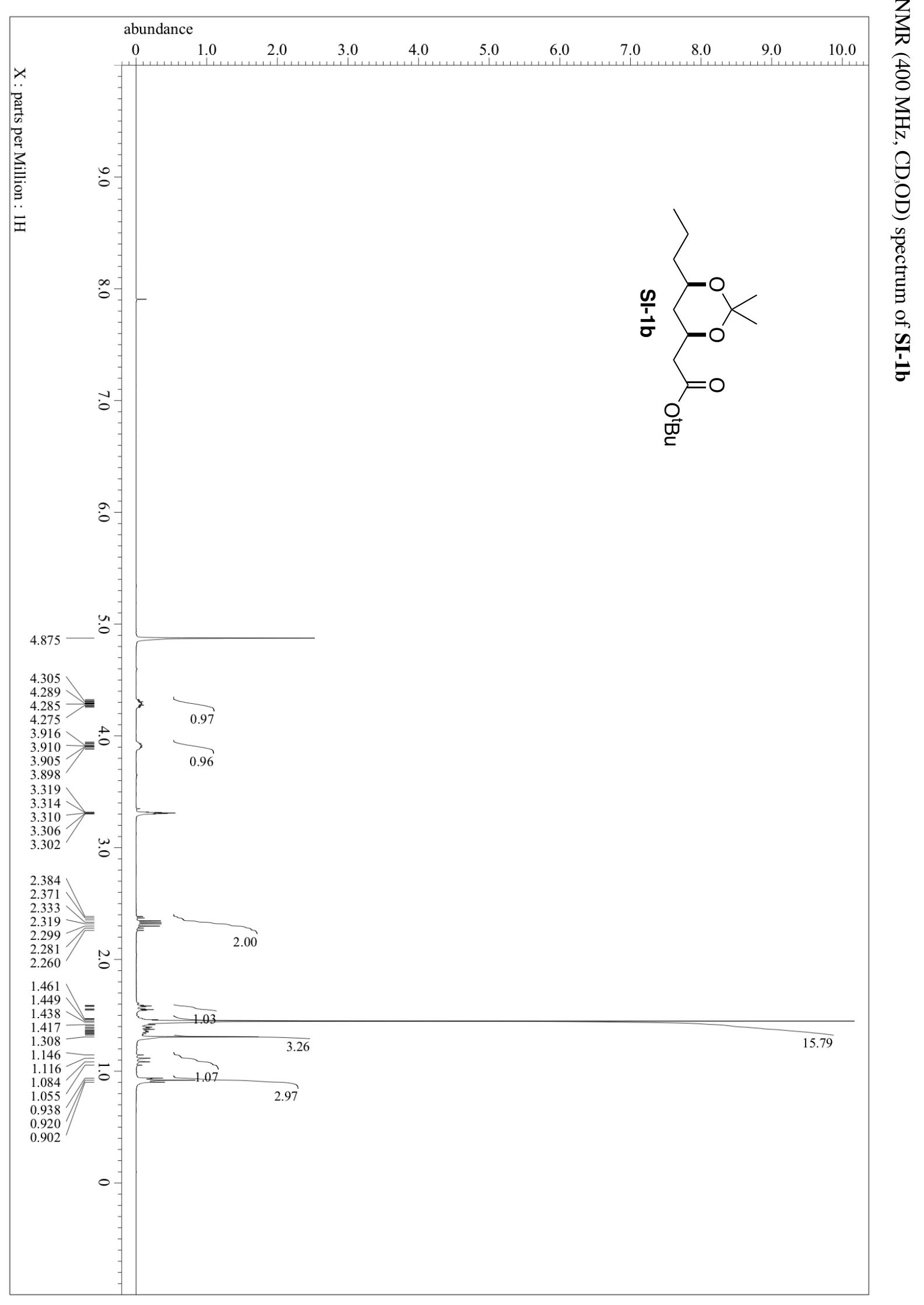




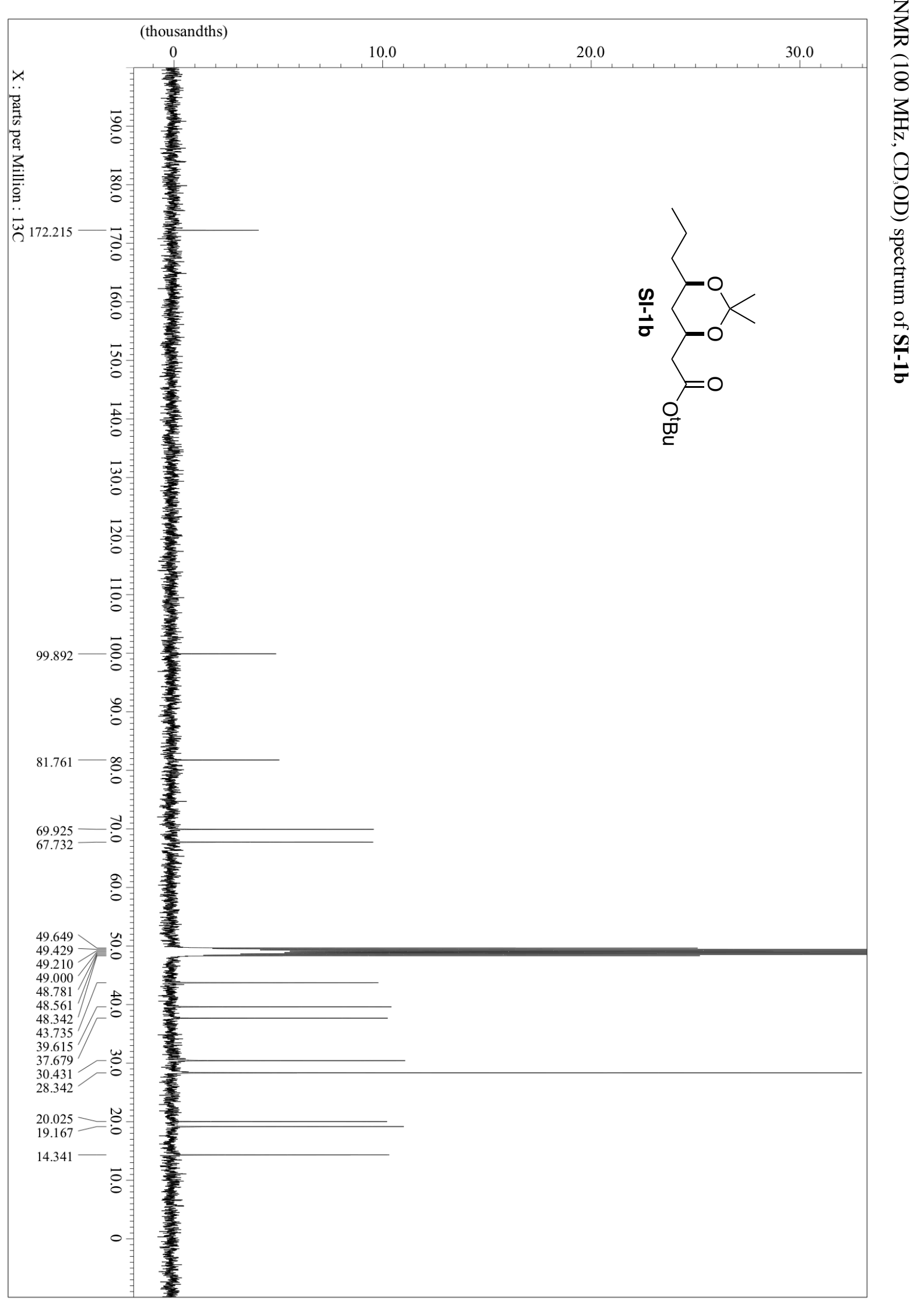




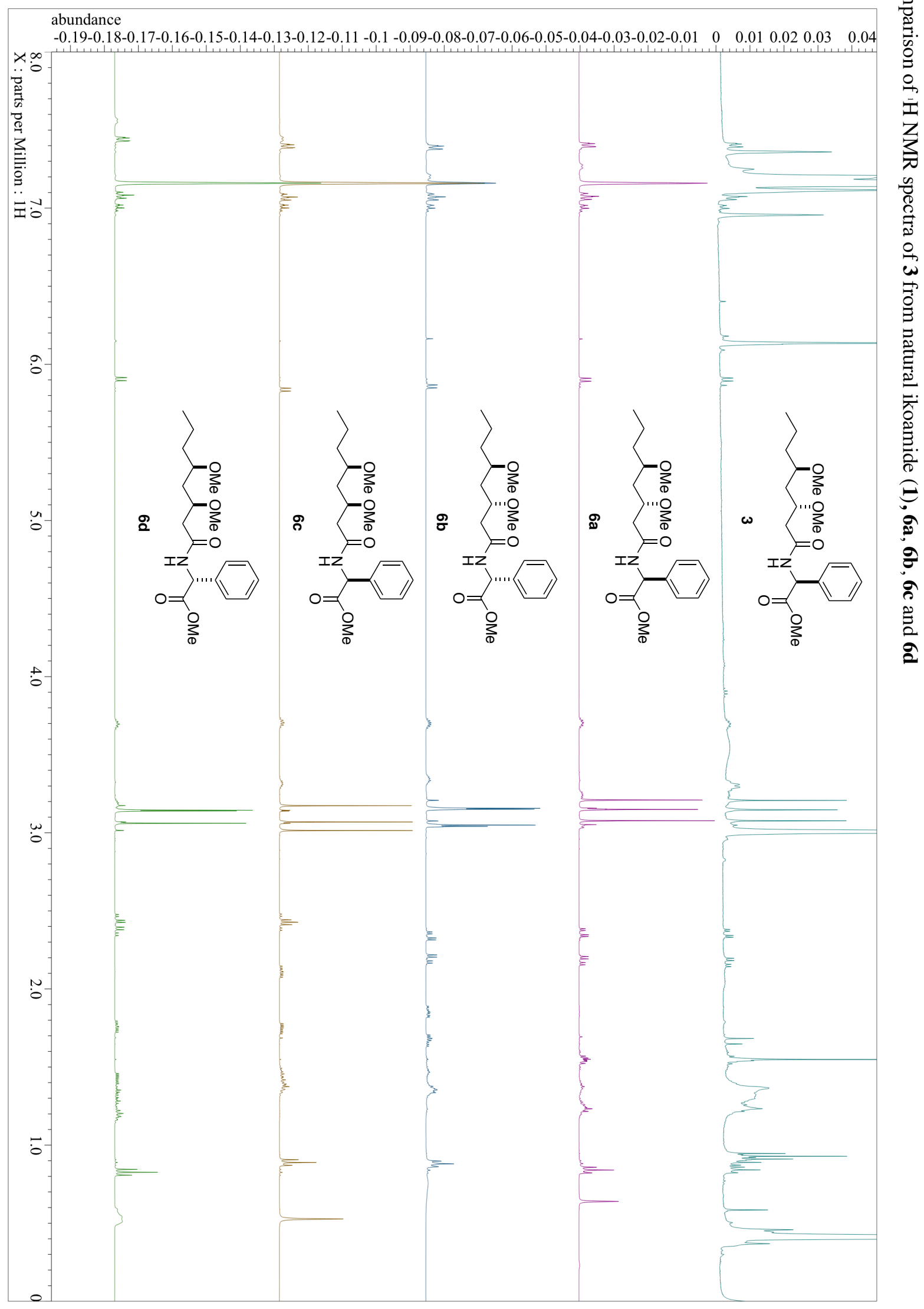




\section{References}

(1) (a) Rychnovsky, S. D.; Skalitzky, D. J. Tetrahedron Lett. 1990, 31, 945. (b) Evans, D. A.; Rieger, D. L.; Gage, J. R. Tetrahedron Lett. 1990, 49, 7099.

(2) Engene, N.; Paul, V. J.; Byrum, T.; Gerwick, W. H.; Thor, A.; Ellisman, M. H. J.phycol. 2013, 49, 1095-1106.

(3) Pruesse, E.; Peplies, J.; Glöckner, F.O. Bioinformatics 2012, 28, 1823-1829.

(4) Talavera, G.; Castresana, J. Syst. Biol. 2007, 56, 564-577.

(5) Castresana, J. Mol. Biol. Evol. 2000, 17, 540-552.

(6) Lefort, V.; Longueville, J.E.; Gascuel, O. Mol. Biol. Evol. 2017, 34, 2422-2424.

(7) Guindon S., Dufayard J.F., Lefort V., Anisimova M., Hordijk W., Gascuel O. Systematic Biology 2010, 59, $307-21$.

(8) Perrière, G.; Gouy, M. WWW-query: an on-line retrieval system for biological sequence banks. Biochimie 1996, 78, 364369.

(9) Ronquist, F.; Teslenko, M.; van der Mark, P.; Ayres, D. L.; Darling, A.; Höhna, S.; Larget, B.; Liu, L.; Suchard, M. A.; Huelsenbem, J. P. Syst. Biol. 2012, 61, 539-542. 